\title{
Review of effective emissions modeling and computation
}

\author{
R. Paoli ${ }^{1}$, D. Cariolle ${ }^{1,2}$, and R. Sausen ${ }^{3}$ \\ ${ }^{1}$ Sciences de l'Univers au CERFACS, URA1875, CERFACS/CNRS, Toulouse, France \\ ${ }^{2}$ Météo France, Toulouse, France \\ ${ }^{3}$ Deutsches Zentrum für Luft- und Raumfahrt (DLR), Institut für Physik der Atmosphäre, Oberpfaffenhofen, Germany
}

Received: 7 December 2010 - Published in Geosci. Model Dev. Discuss.: 19 January 2011

Revised: 25 June 2011 - Accepted: 28 July 2011 - Published: 5 August 2011

\begin{abstract}
An important issue in the evaluation of the environmental impact of emissions from concentrated sources such as transport modes, is to understand how processes occurring at the scales of exhaust plumes can influence the physical and chemical state of the atmosphere at regional and global scales. Indeed, three-dimensional global circulation models or chemistry transport models generally assume that emissions are instantaneously diluted into large-scale grid boxes, which may lead, for example, to overpredict the efficiency of $\mathrm{NO}_{\mathrm{x}}$ to produce ozone. In recent times, various methods have been developed to incorporate parameterizations of plume processes into global models that are based e.g. on correcting the original emission indexes or on introducing "subgrid" reaction rates in the models. This paper provides a review of the techniques proposed so far in the literature to account for local conversion of emissions in the plume, as well as the implementation of these techniques into atmospheric codes.
\end{abstract}

\section{Introduction}

In order to study the impact of anthropogenic emissions of trace gases on the global-scale atmospheric composition, global chemistry transport models (CTM) or global climatechemistry models (CCM) are usually applied (e.g. Cess et al., 1990; Roeckner et al., 1996; Kraaøbl et al., 1999; Zeng and Pyle, 2003; Hauglustaine et al., 2004). This area of research has been investigated over the last two decades mostly for its relevance to the environmental impact of aviation (consult the reviews by Penner et al., 1999; Sausen et al., 2005; Lee et al., 2010). Application of CTM to study the effects of maritime transport has also received growing attention

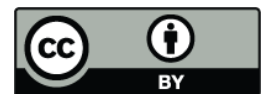

Correspondence to: R. Paoli (roberto.paoli@cerfacs.fr) because of its relevance to important environmental, climate and health challenges (Corbett, 2003; Eyring et al., 2010).

Depending on model resolution the grid boxes of global models have sizes of few degrees in latitudinal and longitudinal directions, and of several hundred metres to few kilometres in vertical direction. The emissions are usually provided by emission inventories on a 2-D latitude-longitude grid, e.g. on a regular $1^{\circ} \times 1^{\circ}$ grid, in the case of surface emissions (Lawrence and Crutzen, 1999; Corbett and Koehler, 2003; Eyring et al., 2007) and on a 3-D latitude-longitude-altitude grid in the case of emissions in the free atmosphere such as emissions from aviation or from lightning (Velders et al., 1994; Brasseur et al., 1998; Meijer et al., 2000). When doing this one implicitly makes the assumption that the emissions are not subject to chemical or physical processes apart from dilution and that they are instantaneously homogeneously distributed into model grid boxes; at least these effects are assumed negligible. However, in many cases, emissions from large line-shaped sources (e.g. aircraft, ships or motorways) and large point sources (e.g. big factories of power plants) result in local concentrations up to several orders of magnitude larger than the background concentrations (Schlager et al., 1997, 2006). Most of the chemical reactions and some of the physical processes non-linearly depend on the concentrations of the species involved (Danilin et al., 1994; Brasseur et al., 1996; Lin et al., 1998; Jaeglé et al., 1998; von Glasow et al., 2003; Song et al., 2003b). Therefore, an impact of the processes has to be expected when the species are diluted into areas of the size of global model grid boxes. For instance, aircraft $\mathrm{NO}_{\mathrm{x}}$ emissions may result in a higher production of ozone when they get instantaneously mixed with background, since this does not account for the effect that the efficiency of $\mathrm{NO}_{\mathrm{x}}$ to produce $\mathrm{O}_{3}$ decreases with increasing $\mathrm{NO}_{\mathrm{x}}$ concentration (Meijer et al., 1997; Kasibhatla et al., 2003). In the case of maritime transport, these effects are even more complicated because of the interaction of $\mathrm{NO}_{\mathrm{x}}$ and $\mathrm{SO}_{\mathrm{x}}$ emissions with exhaust and natural aerosols and

Published by Copernicus Publications on behalf of the European Geosciences Union. 
boundary layer clouds (Kasibhatla et al., 2003; Song et al., 2003a). In recent times different approaches have been made to tackle the problem, in particular in the context of studying the impact of aviation on the global-scale atmospheric composition, e.g. Meijer et al. (1997); Petry et al. (1998); Kraabøl et al. (2002); Cariolle et al. (2009), but also when considering ship emissions (Franke et al., 2008; Huszar et al., 2010). All of them are parameterizations, i.e. they do not explicitly model the processes occurring during the initial dilution and dispersion of the emissions, they rather mimic the effect of the emissions on the large-scale variables such as mean box concentrations of chemical species. The various approaches differ in the theoretical concepts how to mimic the large-scale effects of local emissions. Basically, three different concepts have been proposed so far: Effective Emissions Indexes (EEI), Emission Conversion Factors (ECF) and Effective Reaction Rates (ERR). In these approaches, either the emissions themselves or the relevant reactions rates are modified in the chemical transport equations. Although these methods were conceived or derived for general chemical mechanisms, their implementation into global models mostly focused on $\mathrm{NO}_{\mathrm{x}}-\mathrm{O}_{3}$ chemistry. This is mainly due to the fact that $\mathrm{NO}_{\mathrm{x}}-\mathrm{O}_{3}$ chemistry is strongly non-linear inside the plume due to the high $\mathrm{NO}_{\mathrm{x}}$ concentration, and therefore their distribution is strongly non-homogenous in the CTM grid-boxes containing a plume. Furthermore, plume parameterizations require a good consistency between the plume and the global model: while this is relatively easy to achieve for gaseous chemistry, it is much more difficult for other processes like microphysics of aerosols/contrails and for heterogeneous chemistry.

This paper is organized as follows: the general conservation equations for global models in the presence of emissions from concentrated sources are presented in Sect. 2. Section 3 gives an overview of the models currently used to represent the plume chemical processes. Section 4 presents the main principles of plume parameterizations for use in global models, while Sect. 5 reviews the results of their implementation into either GCM/CTM or regional models. The problem of validation and verification of plume parameterizations is discussed in Sect. 6. Finally, a synthetic comparison among the different methods is presented and conclusions are drawn in Sect. 7.

\section{General formulation of large-scale models in the presence of exhaust plumes}

In order to analyze the different techniques developed to integrate the parameterization of reactive plumes into global models, it can be useful to examine the global mass balance equations starting from the basic mass conservation laws for a mixture of reacting species in a fluid: $\frac{\partial C_{k}}{\partial t}+\nabla \cdot\left(C_{k} \mathbf{u}\right)+\nabla \cdot\left(D_{k} \nabla C_{k}\right)=E_{k}+\omega_{k}, \quad k=1, \ldots, N_{\mathrm{s}}$

where $N_{\mathrm{s}}$ is the number of species, $\mathbf{u}$ is the fluid velocity, while $C_{k}, D_{k}, E_{k}$ and $\omega_{k}$ are, respectively, the concentration, the molecular diffusion coefficient, the emission rate and chemical sources of species $k$. The chemical sources account for all reaction, $j=1, \ldots, N_{r}$, contributing to the production/removal of species $k$ :

$\omega_{k}=\sum_{j=1}^{N_{r}} \Delta v_{k_{j}} K_{j} C_{k_{j_{1}}}{ }^{v_{j_{1}}} C_{k_{j_{2}}}{ }^{v_{k_{j_{2}}}} \equiv \omega_{k}\left(C_{1}, . ., C_{N_{\mathrm{s}}}\right)$

where $K_{j}$ is the rate of reaction $j, \Delta v_{k_{j}}$ is the difference between the forward and backward stoichiometric coefficients of species $k$ in reaction $j$, and $k_{j_{1}}$ and $k_{j_{2}}$ denote the two species involved in reaction $j$, with $v_{k_{1}}$ and $v_{k_{j_{2}}}$ the corresponding (forward) stoichiometric coefficients.

Large-scale atmospheric models do not directly solve Eq. (1) but an "average" form of these equations, where average can be interpreted either in a statistical sense as an ensemble mean or a Reynolds average, or as a grid average over a large computational cell (Galmarini et al., 2008). In the latter case, one can defined a grid-average for any variable $\varphi$ as:

$\bar{\varphi}(\mathbf{x}, t)=\frac{1}{V} \int_{V} \varphi(\mathbf{y}, t) d \mathbf{y}$

where $V$ and $\mathbf{x}$ are the volume and the center of the cell, respectively, and a perturbation around the mean $\varphi^{\prime}(\mathbf{x}, t)=$ $\varphi(\mathbf{x}, t)-\bar{\varphi}(\mathbf{x}, t)$. With these definitions, Eq. (1) becomes

$\frac{\partial \bar{C}_{k}}{\partial t}+\nabla \cdot\left(\bar{C}_{k} \overline{\mathbf{u}}\right)+\nabla \cdot\left(D_{t} \nabla \bar{C}_{k}\right)=\bar{E}_{k}+\bar{\omega}_{k}$

where the turbulent or sub-grid scale diffusion is modeled using classical Boussinesq approximation: $\overline{C_{k}^{\prime} \mathbf{u}^{\prime}}=-D_{\text {turb }} \nabla \bar{C}_{k}$ and $D_{t} \equiv D_{k}+D_{\text {turb }}$ (in practice $D_{t} \simeq D_{\text {turb }}$ in the atmosphere). Introducing the total derivative operator

$\frac{D \varphi}{D t} \equiv \frac{\partial \varphi}{\partial t}+\nabla \cdot(\overline{\mathbf{u}} \varphi)+\nabla \cdot\left(D_{t} \nabla \varphi\right)$

for any variable $\varphi$, Eq. (4) can be recast as

$\frac{D \bar{C}_{k}}{D t}=\bar{E}_{k}+\bar{\omega}_{k}$

The grid-averaged emission rate $\bar{E}_{k}$ in the right-hand side of Eq. (6) can be reconstructed using inventories of aircraft or ship emissions along prescribed air or see corridors:

$\bar{E}_{k}=\mathrm{EI}_{k} \bar{S}_{\mathrm{f}}$.

with $\mathrm{EI}_{k}$ the species emission index and $S_{\mathrm{f}}$ the fuel consumption per unit volume. The grid-averaged chemical source $\bar{\omega}_{k}$ contains various non-linear sub-grid scale terms involving $C_{k}$ and $K_{j}$. The sub-grid contribution due to the reaction rates 


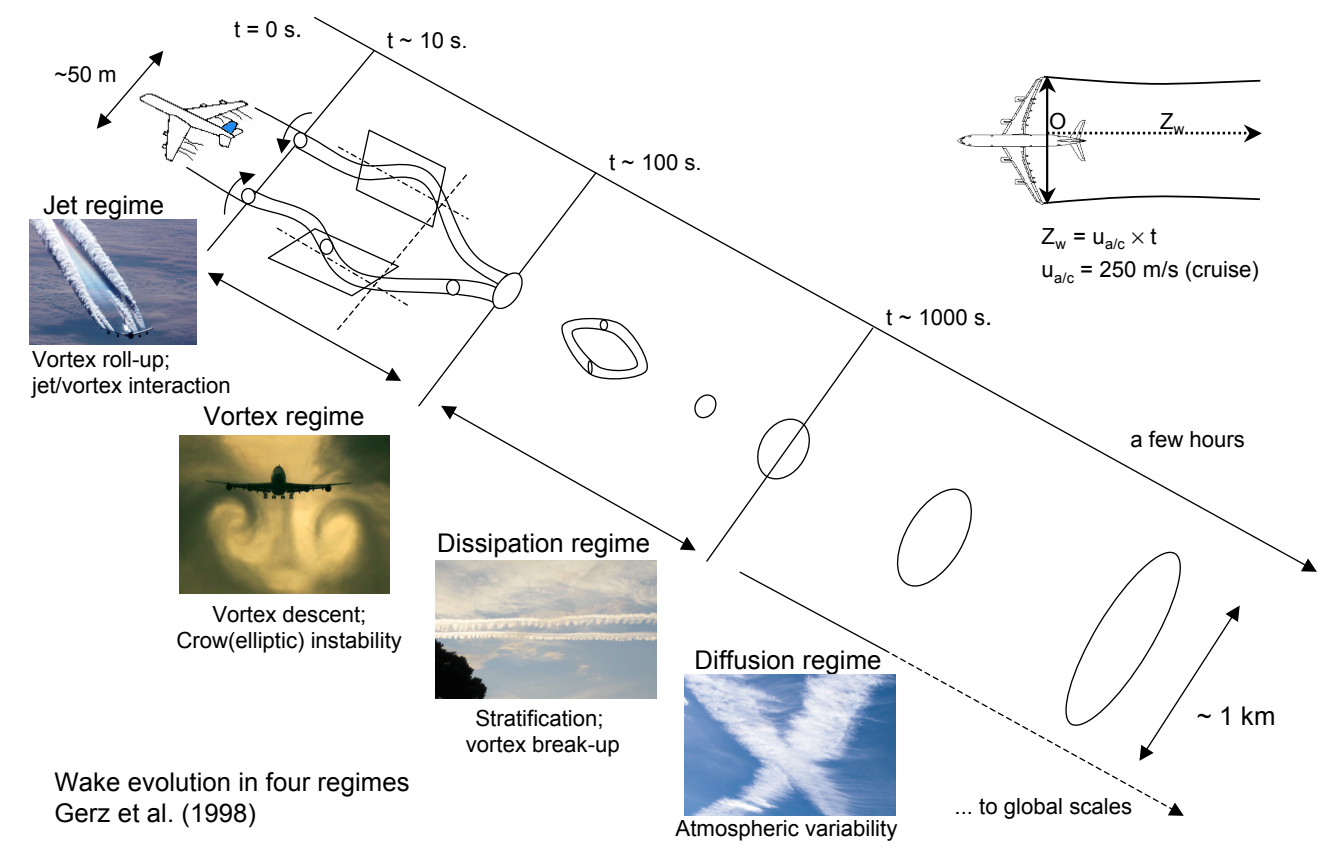

Fig. 1. Sketch of aircraft plume evolution according to the classification of aircraft wakes in four regimes (Paoli, 2010).

can be neglected because of their weak dependence on temperature, i.e. $\overline{K_{j} \varphi} \simeq \overline{K_{j}} \bar{\varphi}$ for any variable $\varphi$. Hence, averaging Eq. (2) and using Eq. (3) yields

$$
\begin{aligned}
\bar{\omega}_{k}=\sum_{j=1}^{N_{\mathrm{r}}^{\prime}} \Delta v_{k_{j}} \bar{K}_{j} \bar{C}_{k_{j_{1}}} & +\sum_{j=1}^{N_{\mathrm{r}}^{\prime \prime}} \Delta v_{k_{j}} \bar{K}_{j} \bar{C}_{k_{j_{1}}} \overline{C_{k_{j_{2}}}} \\
& +\sum_{j=1}^{N_{\mathrm{r}}^{\prime \prime}} \Delta v_{k_{j}} \overline{K_{j}} \overline{C_{k_{j_{1}}}^{\prime} C_{k_{j_{2}}}^{\prime}}
\end{aligned}
$$

where $N_{\mathrm{r}}^{\prime}$ and $N_{\mathrm{r}}^{\prime \prime}$ (with $N_{r} \equiv N_{\mathrm{r}}^{\prime}+N_{\mathrm{r}}^{\prime \prime}$ ) indicate the number of uni-molecular reactions $\left(v_{k_{j_{1}}}=1, v_{k_{j_{2}}}=0\right)$ and bimolecular reactions $\left(v_{k_{j_{1}}}=v_{k_{j_{2}}}=1\right)$, respectively. (Chemical reactions with higher molecularity are not common in the atmosphere and will not be considered here). The first two summations in the right-hand side of Eq. (8) contain gridaveraged variables that are directly transported by the global model. On the other hand, the last summation contains nonlinear sub-grid scale fluctuations of species concentrations $\overline{C_{k_{j_{1}}}^{\prime} C_{k_{j_{2}}}^{\prime}}$ which are in general unknown. If chemical species are not well mixed within a computational cell (as in the case of emissions from concentrated sources) these terms cannot be neglected and have to be modeled or parameterized. Two main strategies can then be developed. The first strategy consists in modifying the emissions to take into account the subgrid plume transformations that cannot be resolved by the global model. Denoting by

$$
\begin{aligned}
\bar{\omega}_{k}\left(\bar{C}_{1}, . ., \bar{C}_{N_{\mathrm{s}}}\right) & \equiv \sum_{j=1}^{N_{\mathrm{r}}^{\prime}} \Delta v_{k_{j}} \bar{K}_{j} \bar{C}_{k_{j_{1}}} \\
& +\sum_{j=1}^{N_{\mathrm{r}}^{\prime \prime}} \Delta v_{k_{j}} \bar{K}_{j} \bar{C}_{k_{j_{1}}} \overline{C_{k_{j_{2}}}}
\end{aligned}
$$

the contributions of chemical sources that depend exclusively on transported grid-averaged quantities and using Eq. (8), Eq. (6) can be formally recast as

$$
\frac{D \bar{C}_{k}}{D t}=\bar{E}_{k}^{\mathrm{eff}}+\bar{\omega}_{k}\left(\bar{C}_{1}, . ., \bar{C}_{N_{\mathrm{s}}}\right)
$$

where $\bar{E}_{k}^{\text {eff }}$ are modified or "effective" emissions. The second strategy consists in parameterizing the sub-grid chemical sources such that Eq. (6) becomes

$$
\frac{D \bar{C}_{k}}{D t}=\bar{E}_{k}+\bar{\omega}_{k}\left(\bar{C}_{1}, . ., \bar{C}_{N_{\mathrm{s}}}\right)+\sum_{j=1}^{N_{\mathrm{r}}^{\prime \prime}} \Delta v_{k_{j}} \bar{K}_{j}^{\mathrm{eff}} \bar{C}_{k_{j_{1}}} \bar{C}_{k_{j_{2}}}
$$

where $\bar{K}_{j}^{\text {eff }}$ are "effective" reaction rates. As described in detail in the following sections, the two strategies differ mainly in the way they account for the chemical transformations in the plume. In the methods based on effective emissions (Effective Emissions Indices, EEI ad Emission Conversion Factors, ECF), the source terms $E_{k}$ are rescaled such that concentrations match the values obtained from smallscale (generally plume) models; hence special care has to be 
view from the side

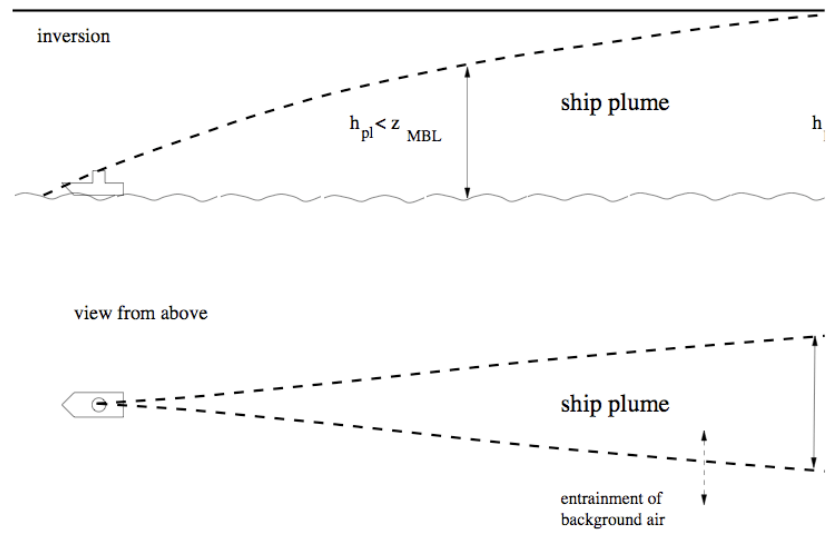

Fig. 2. Sketch of ship plume evolution in the marine boundary layer (von Glasow et al., 2003).

taken to insure chemical conservation. In the effective reaction rates (ERR), the reaction rates are modified so that the overall species production/destruction match the values obtained from the plume model without changing the emissions, which automatically guarantees conservation. Whatever strategy is chosen, Eq. (10) or Eq. (11) contain averaged ("bar") quantities that are known at run time by the global model, all the external modeling effort is condensed into either $\bar{E}_{k}^{\text {eff }}$ or $\bar{K}_{j}^{\text {eff }}$.

\subsection{Aircraft and ship plumes}

It is important to point out that parameterizations are not meant to reproduce the actual evolution of exhaust plumes. In fact, the resolution used in large-scale models (a few hundred kilometers) does not allow to resolve the dynamical and physico-chemical processes occurring at the scales of the plume (which range from meters to a few kilometers once trace gases get mixed with background). This is shown for example in Fig. 1 which sketches the dispersion of exhausts in aircraft plumes according to the representation proposed by Gerz et al. (1998). The process is initially driven by the dynamics of the wake vortices generated by the airplane (primary vortex pair). During the first few seconds after emission, the exhaust material is trapped around the wake vortices (jet regime), which later start to sink by the mutually induced downward velocity (vortex regime). Part of the exhausts is detrained into a secondary vortex pair that forms by the buoyancy force induced by atmospheric stratification while the majority of exhausts undergoes a complex instability process that leads to the vortex break-up, turbulence production and release of exhausts in the atmosphere (dissipation regime). In the final diffusion regime the exhausts get diluted to background level via atmospheric processes (turbulence, radiation transport, etc.) usually within 2 to $12 \mathrm{~h}$
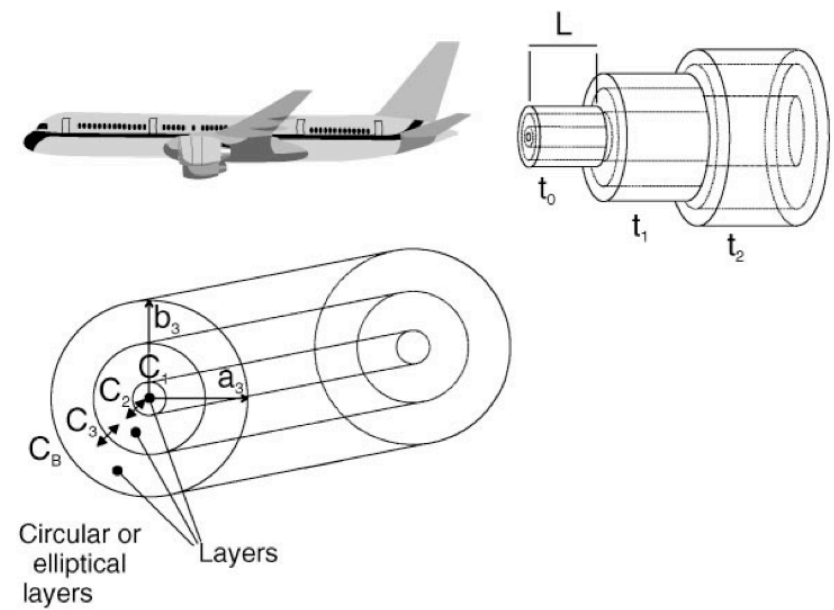

Fig. 3. Multilayer plume model of an aircraft plume. Reprinted from Kraabøl et al. (2000b), Atmospheric Environment, Copyright (2000), with permission.

(see Schumann et al., 1998 for a collection of dilution data from several experimental campaigns).

Ship plumes are another example of plumes from concentrated sources (see the sketch in Fig. 2). In this case the exhausts are released at the ship stack and initially disperse in the vertical direction before reaching the top of the marine boundary layer. Afterwards, the dispersion takes place mostly in the horizontal direction until complete dilution. This process can strongly depend on the background conditions and in particular on the typology of the boundary layer as well as the initial buoyancy flux at the stack of the ship (Chosson et al., 2008).

The most accurate way to model the evolution of reactive species in such complex scenarios is to rely on threedimensional large-eddy simulations (LES) that cover the entire lifetime of the plume. However, although feasible, these simulations are still extremely demanding of computational resources - CPU power, memory and data storage - especially if several cases have to be run for a large number of different conditions. High-resolution LES of reactive wakes may require up to several million grid-points for tens of seconds to minutes plume age simulations (Lewellen and Lewellen, 2001a,b; Paoli et al., 2004; Chosson et al., 2008; Paugam et al., 2010). As detailed in the following sections, the alternative to such expensive three-dimensional simulations is to rely on plume parameterizations that provide surrogates for $\bar{E}_{k}^{\text {eff }}$ or $\bar{K}_{j}^{\text {eff }}$. Then, data from detailed LES or from experiments can be used to calibrate these parameters. 
Table 1. Diffusion parameters obtained from in situ measurements (Schumann et al., 1995).

\begin{tabular}{ccccccc}
\hline$D_{\mathrm{h}}\left(\mathrm{m}^{2} \mathrm{~s}^{-1}\right)$ & $D_{\mathrm{v}}\left(\mathrm{m}^{2} \mathrm{~s}^{-1}\right)$ & $D_{\mathrm{s}}\left(\mathrm{m}^{2} \mathrm{~s}^{-1}\right)$ & $s\left(\mathrm{~s}^{-1}\right)$ & $\sigma_{\mathrm{h}, 0}(\mathrm{~m})$ & $\sigma_{\mathrm{v}, 0}(\mathrm{~m})$ & $\sigma_{\mathrm{s}, 0}(\mathrm{~m})$ \\
\hline 10 & 0.3 & 1 & 0.004 & 200 & 50 & 0 \\
\hline
\end{tabular}

\section{Representation of plume processes}

This section examines the different models that have been developed in the literature to parameterize the processes occurring in plumes like those sketched in Figs. 1 and 2. The common feature of these models is that they use a finite (generally small) number of parameters to represent the structure of the plume and the distribution of exhausts within it. These parameters evolve in time and obey ordinary differential equations (i.e. they do not explicitly depend on space), so in this sense all these models are zero-dimensional. Examples of key parameters are the mean concentration within the plume in Gaussian plume models, or the mean concentration within radial sectors of the plume in Multilayered Plume models that will be described below. An important aspect that differentiate these models is indeed the way of representing mixing in the interior of the plume and entrainment of ambient air from the exterior. The concentrations obtained from small-scale plume models will be denoted by low-case symbols, $c_{k}$ to avoid confusion with variables $C_{k}$ defined in Sect. 2 that pertain to large-scale Chemical Transport Models.

\subsection{Instantaneous Dispersion (ID)}

This simple parameterization represents the way emissions are usually handled in global models: the emissions are instantaneously diluted to the scales of a large control volume (e.g. the computational cell of a global model). Since this parameterization does not require any plume specification, only one set of ordinary differential equations for the mean concentrations $c_{k}^{\mathrm{ID}}$ within the control volume is then sufficient to represent the process:

$\frac{d c_{k}^{\mathrm{ID}}}{d t}=E_{k, t_{0}}+\omega_{k}\left(c_{1}^{\mathrm{ID}}, . ., c_{N_{\mathrm{s}}}^{\mathrm{ID}}\right)$

where the first term in the right-hand side means that emissions are non-zero only at time $t=t_{0}$ while the chemical sources $\omega_{k}$ follow the same law as in Eq. (2).

\subsection{Single plumes}

In the Single Gaussian Plume model, two sets of ordinary differential equations are solved: one for the mean concentration inside the plume $c_{k}^{\mathrm{p}}$ and one for the background concentration $c_{k}^{\mathrm{a}}$ :

$$
\frac{d c_{k}^{\mathrm{p}}}{d t}=E_{k, t_{0}}+\omega_{k}\left(c_{1}^{\mathrm{p}}, . ., c_{N_{\mathrm{s}}}^{\mathrm{p}}\right)+\left(c_{k}^{\mathrm{p}}-c_{k}^{\mathrm{a}}\right) \frac{1}{V_{\mathrm{p}}} \frac{d V_{\mathrm{p}}}{d t}
$$

$$
\frac{d c_{k}^{\mathrm{a}}}{d t}=\omega_{k}\left(c_{1}^{\mathrm{a}}, . ., c_{n}^{\mathrm{a}}\right)
$$

where $V_{\mathrm{p}}$ denotes the volume of the plume and the last term in Eq. (13) represents plume dilution. In the case of aircraft emissions, plume is asymmetric and anisotropic at cruise altitude because of atmospheric stratification and wind shear. A classical way of defining the dispersion of the plume is using a matrix of variances that follow a Gaussian distribution in the plane perpendicular to the flight path: $\sigma_{\mathrm{h}}$ and $\sigma_{\mathrm{v}}$ for the horizontal and vertical variances, and $\sigma_{\mathrm{s}}$ the diagonal term of the matrix accounting for the deformation of the plume by vertical wind shear. Analytical solutions for these variances were obtained by Konopka (1995):

$$
\begin{aligned}
\sigma_{h}^{2} & =\sigma_{h, 0}^{2}+2\left(s \sigma_{s, 0}^{2}+D_{\mathrm{h}}\right) t+\left(2 s D_{\mathrm{s}}+s^{2}+\sigma_{\mathrm{v}, 0}^{2}\right) t^{2} \\
& +\frac{2}{3} s^{2} D_{\mathrm{v}} t^{3} \\
\sigma_{\mathrm{v}}^{2} & =\sigma_{\mathrm{v}, 0}^{2}+2 D_{\mathrm{v}} t \\
\sigma_{\mathrm{s}}^{2} & =\sigma_{\mathrm{s}, 0}^{2}+\left(s \sigma_{v, 0}^{2}+2 D_{\mathrm{s}}\right) t+s D_{\mathrm{v}} t^{2}
\end{aligned}
$$

where $D_{\mathrm{v}}, D_{\mathrm{h}}$ and $D_{\mathrm{s}}$ denote the vertical, horizontal, and shear diffusion coefficients, respectively, while $s$ denotes the wind shear. The subscript 0 in the above equations refer to a plume age $t_{0}$ when the expansion of the plume can be approximated by a pure diffusion process (typically the beginning of the diffusion regime as discussed in the previous section). The emissions in Eq. (13) should also be interpreted as already diluted at the spatial scale of the plume corresponding to $t_{0}$. Table 1 summarizes the values of coefficients in Eqs. (15)-(17) obtained from in situ measurements (Schumann et al., 1995). The volume of the plume and the crosssectional area $A_{\mathrm{p}}$ can be obtained from Eqs. (15)-(16) as (Konopka, 1995):

$$
\begin{aligned}
& A_{\mathrm{p}}(t)=n^{2} \pi\left(\sigma_{\mathrm{h}}^{2} \sigma_{\mathrm{v}}^{2}-\sigma_{\mathrm{s}}^{4}\right)^{1 / 2} \\
& V_{\mathrm{p}}(t)=A_{\mathrm{p}}(t) L_{\text {path }}
\end{aligned}
$$

where $L_{\text {path }}$ denotes a reference length along flight direction, e.g. the distance flown by the aircraft per second, $L_{\text {path }}=$ $250 \mathrm{~m}$ at cruise speed (Kraabøl et al., 2000b), while $n$ determines the fraction of the Gaussian distribution containing the exhaust and sets the width of the plume. For example, choosing $n=2$ corresponds to incorporate $98 \%$ of exhaust (Petry et al., 1998).

In the case of ship emissions, the vertical and horizontal variances of the plume (with respect to the ship direction) can be derived by matching Gaussian solutions to empirical dispersion parameters (Seinfeld and Pandis, 2006). For 
Table 2. Diffusion parameters for ship plume dispersion used by von Glasow et al. (2003) ( $\alpha$ ad $\beta$ are best guest values).

\begin{tabular}{cccc}
\hline$\alpha$ & $\beta$ & $\sigma_{\mathrm{h}, 0}(\mathrm{~m})$ & $\sigma_{\mathrm{v}, 0}(\mathrm{~m})$ \\
\hline 0.75 & 0.6 & 10 & 5
\end{tabular}

example, Hanna et al. (1985) and Song et al. (2003b) determined $\sigma_{\mathrm{h}}$ and $\sigma_{\mathrm{v}}$ by the standard deviations of turbulent velocity fluctuations and the integral time scales of turbulence whereas von Glasow et al. (2003) proposed the simpler expressions

$\sigma_{\mathrm{h}}=\sigma_{\mathrm{h}, 0}\left(\frac{t}{t_{0}}\right)^{\alpha}$

$\sigma_{\mathrm{v}}=\sigma_{\mathrm{v}, 0}\left(\frac{t}{t_{0}}\right)^{\beta}$

where subscript 0 identifies a reference time, for example $t_{0}=1 \mathrm{~s}$ after emission, while $\alpha$ and $\beta$ are are the plume expansion rates that depend on the specific atmospheric conditions. von Glasow et al. (2003) also provided "best guest values" of 0.75 and 0.6 for $\alpha$ and $\beta$, respectively, based on the work by Durkee et al. (2000) (see Table 2). Once the variances are specified, the ship plume area can be reconstructed using Eq. (18) (with $\sigma_{\mathrm{s}} \equiv 0$ ), in particular taking $n=1 / \sqrt{8}$, gives $A_{\mathrm{p}}=\pi / 8 \sigma_{\mathrm{h}} \sigma_{\mathrm{v}}$ which corresponds to a semi-elliptical cross-section (von Glasow et al., 2003).

The Multilayered Plume model was first developed by Melo et al. (1978) and Vilà-Guerau de Arellano et al. (1990) as a generalization of the single plume model for aircraft emissions. The plume is indeed divided into $N_{\mathrm{L}}$ concentric rings or layers in order to represent the concentration distributions (see Fig. 3). A number of rings $4<N_{\mathrm{L}}<16$ has been typically used in the literature (Melo et al., 1978; Meijer, 2001; Kraabøl et al., 2000b; Vohralik et al., 2008). In this model, Eqs. (13)-(14) are replaced by the following set of equations for the mean concentration $c_{k}^{l}$ inside each ring $l$ of the plume:

$$
\begin{aligned}
\frac{d c_{k}^{l}}{d t}=E_{k, t_{0}} & +\omega_{k}\left(c_{1}^{l}, . ., c_{N_{\mathrm{s}}}^{l}\right) \\
& +f\left(c_{k}^{1}, . ., c_{k}^{N_{\mathrm{L}}} ; A_{1}, . ., A_{N_{\mathrm{L}}}\right) \frac{1}{V_{\mathrm{p}}} \frac{d V_{\mathrm{p}}}{d t}
\end{aligned}
$$

where $A_{l}$ and $V_{l} \equiv A_{l} L_{\text {path }}$ are, respectively, the area and the volume of the ring; $V_{\mathrm{p}} \equiv \sum_{l=1}^{N_{\mathrm{L}}} V_{l}$, and $f$ is a function that parameterizes the mixing of species across different layers of the plume (Meijer, 2001; Kraabøl et al., 2000b). The concentration in the outermost layer corresponds to the ambient concentration, $c_{k}^{N_{\mathrm{L}}} \equiv c_{k}^{\mathrm{a}}$, while the overall mean concentration in the plume is given by

$c_{k}^{\mathrm{p}}=\frac{\sum_{l=1}^{N_{\mathrm{L}}} c_{k}^{l} V_{l}}{\sum_{l=1}^{N_{\mathrm{L}}} V_{l}} \equiv \frac{\sum_{l=1}^{N_{\mathrm{L}}} c_{k}^{l} V_{l}}{V_{\mathrm{p}}}$.

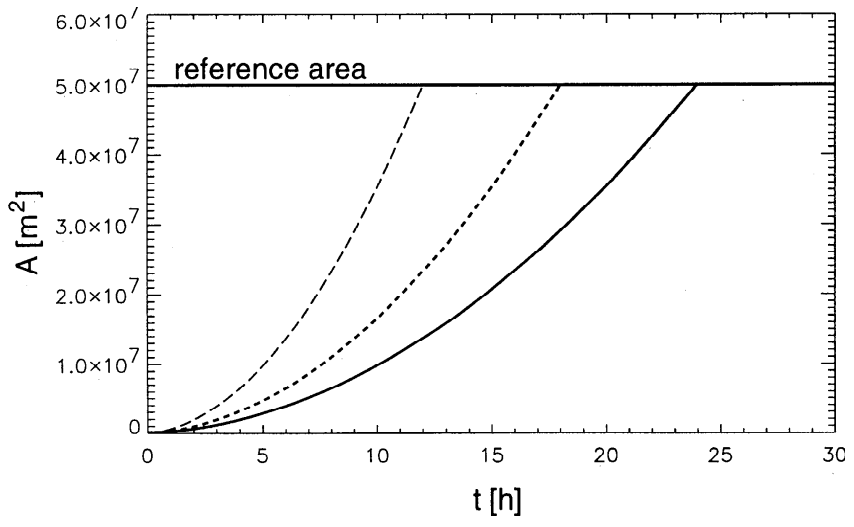

Fig. 4. Evolution of the plume cross-section $A_{\mathrm{p}}$ showing the plume lifetime $t_{\mathrm{p}}=t_{\text {ref }}$ that corresponds to the intersecton with the reference area $A_{\text {ref }}$. Solid line: $t_{\text {ref }}=24 \mathrm{~h}$; dashed line: $t_{\text {ref }}=18 \mathrm{~h}$; long-dashed line: $t_{\text {ref }}=12 \mathrm{~h}$. Reprinted from Petry et al. (1998). An edited version of this paper was published by AGU. Copyright (1998) American Geophysical Union.

It is interesting to rewrite the last term in the right-hand side of Eq. (13) or Eq. (22) in terms of the entrainment rate $\omega_{\mathrm{E}}$ or its inverse, the entrainment time $\tau_{\mathrm{E}}$ :

$\omega_{\mathrm{E}} \equiv \frac{1}{\tau_{\mathrm{E}}}=\frac{1}{V_{\mathrm{p}}} \frac{d V_{\mathrm{p}}}{d t} \equiv \frac{1}{A_{\mathrm{p}}} \frac{d A_{\mathrm{p}}}{d t}$

which represents the instantaneous expansion rate of the plume whose evolution can be computed analytically using Eqs. (15)-(19). The above equation suggests that in the limit $\tau_{\mathrm{E}} \rightarrow 0$, the plume concentration $c_{k}^{\mathrm{p}}$ relaxes instantaneously towards the ambient concentration $c_{k}^{\text {a }}$ (see Eqs. 13 or 22): in this case the single plume models degenerate into the instantaneous dispersion model and Eq. (12) is recovered. It is worth remarking that $\tau_{\mathrm{E}}$ is a measure of the instantaneous dilution of the plume and, as such, it does not provide any indication about the "lifetime" of the plume, which is a measure of the timescale over which exhausts can be considered diluted to background level. As discussed in the next section, this point is particularly relevant to the parameterization of plume processes into global models whose spatial and temporal resolutions do not allow to reproduce the entire evolution of the plume.

Instead of modeling the structure of the plume by Gaussian plume theory, Schumann et al. (1998) proposed to parameterize the entire evolution of aircraft plumes (including the initial non-Gaussian phases dominated by the aircraft wake, see Fig. 1), using experimental data of conserved scalars in the plume (essentially $\mathrm{CO}_{2}$ and $\mathrm{NO}_{\mathrm{x}}$ ). This results in the simple formula

$A_{\mathrm{p}}(t)=A_{\mathrm{p}}\left(t_{0}\right)\left(\frac{t}{t_{0}}\right)^{\alpha}$

where $t_{0}=10 \mathrm{~s}$. sets the beginning of the vortex regime (Sect. 2.1) and $A_{\mathrm{p}}\left(t_{0}\right)=0.88 \times 10^{-4} \mathrm{~km}^{2}$ is the corresponding plume area, while $\alpha=0.8$ is a fit from experimental data. 


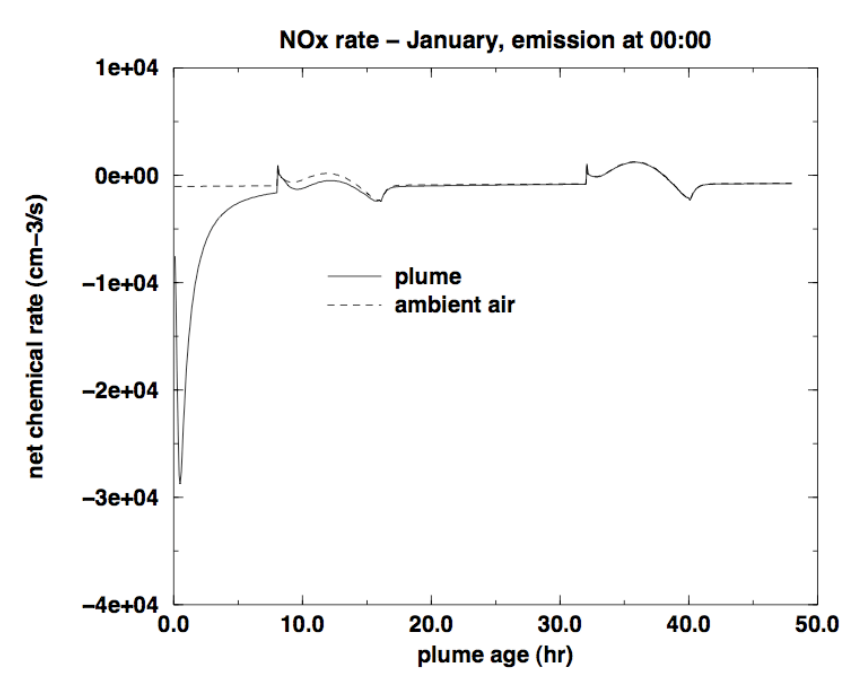

Fig. 5. Evolution of plume and background $\mathrm{NO}_{\mathrm{x}}$ chemical rate. The plume lifetime $t_{\mathrm{p}}=t_{\text {mix }}$ is defined as the time when the difference between the two rates is below a threshold value (Meijer, 2001).

\subsubsection{Choice of the plume lifetime $t_{\mathrm{p}}$}

In the literature, various definitions have been proposed for the plume lifetime $t_{\mathrm{p}}$. Petry et al. (1998) suggested to take

$t_{\mathrm{p}} \equiv t_{\mathrm{ref}}$

where $t_{\text {ref }}$ is the "dispersion" time, i.e. the time when the plume reaches the dimensions of a reference area $A_{\text {ref }}$, for example the 2-D latitude-longitude grid box of a global model (see Fig. 4). For typical grid resolutions employed in CTM, $A_{\text {ref }} \simeq 5 \times 10^{7} \mathrm{~m}^{2}$ and $t_{\text {ref }} \simeq 18 \mathrm{~h}$ although this value strongly depends on the actual resolution of the global model and on the dispersion parameters of the atmosphere. Meijer (2001), Karol et al. (2000) and Kraabøl et al. (2000b) defined the plume lifetime as

$t_{\mathrm{p}} \equiv t_{\mathrm{mix}}$

where $t_{\text {mix }}$ represents the "mixing" time, i.e. the time when the $\mathrm{NO}_{\mathrm{x}}$ chemical conversion rate in the plume and in the ambient air are sufficiently close (in practice, when the difference falls below a small threshold value, see Fig. 5). As shown by Karol et al. (2000), this time can vary significantly with the background conditions, the characteristics of the atmospheric turbulence and the location of the plume, e.g. if it is already inside the North Atlantic Flight Corrior (NAFC) or outside of it. Kraabøl et al. (2002) chose the life time as the minimum between the dispersion and the mixing times:

$t_{\mathrm{p}} \equiv \operatorname{MIN}\left(t_{\mathrm{ref}}, t_{\mathrm{mix}}\right)$.

A rather different approach has been developed by Cariolle et al. (2009) to represent plume dilution. This is based on the fact that the non-linear chemical processes within the plume are efficient up to a threshold value of exhaust concentration $c_{\text {lim. }}$. The plume is then constituted by the air masses with concentration in excess with respect to $c_{\text {lim }}$ :

$$
\begin{aligned}
& V_{\mathrm{p}}=V: c-c_{\lim }>0, \\
& m_{\mathrm{p}}^{*}=\int_{V_{\mathrm{p}}}\left(c-c_{\lim }\right) d V_{\mathrm{p}}
\end{aligned}
$$

where $c$ indicates the concentration of a conserved species in the plume (e.g. $\mathrm{NO}_{\mathrm{x}}$ ) and $V$ is a control volume. The excess of exhaust mass $m_{\mathrm{p}}^{*}$ decreases monotonically in time until it reaches zero at $t=t_{\text {lim }}$, which is taken as the plume lifetime (see sketch in Fig. 6):

$t_{\mathrm{p}}=t_{\text {lim }}$.

All the definitions of plume lifetime, Eqs. (26)-(31), implicitly assume that plumes do not overlap. However, in regions of dense traffic individual plumes can merge and the air masses with high exhaust concentration can have longer lifetime. Meilinger et al. (2005) determined the average plume encounter time $t_{l}$ hours for the North Atlantic Flight Corridor (NAFC). The airplane flux density $\phi$ in the Corridor (assumed uniform) is defined as

$\phi=\frac{\dot{N}_{\mathrm{p}}}{A_{\mathrm{FC}}}$

where $\dot{N}_{\mathrm{p}}$ is the number of airplane per unit time flying throguh the Corridor area $A_{\mathrm{FC}}$. To obtain the encounter time $t_{l}$, one has to integrate Eq. (32), impose $N_{\mathrm{p}} \equiv 1$ and substitute $A_{\mathrm{FC}}$ with one of the expressions for plume area $A_{\mathrm{p}}$ introduced in Sect. 3.2:

$N_{\mathrm{p}} \equiv 1=\int_{t_{0}}^{t_{l}} \phi A_{\mathrm{p}}(t) d t$

which is an implicit relation in $t_{l}$. If the simple formula Eq. (25) is used for $A_{\mathrm{p}}$, an analytical expression can obtained:

$t_{l}=t_{0}\left(1+\frac{1+\alpha}{\phi A_{\mathrm{p}}\left(t_{0}\right) t_{0}}\right)^{1 /(1+\alpha)}$

as summarized in Fig. 7. The encounter time is an "objective" definition of plume lifetime in the sense that it does not depend on a specific plume or global model but only on the average aircraft flux density (see Fig. 7). The Single Plume or the Multilayered Plume models should be strictly valid only if the diffusion process is efficient enough for $t_{\text {ref }}$ or $t_{\text {mix }}$ to be lower than the average plume encounter time $t_{l}$. This is generally satisfied: for example, Petry et al. (1998) and Meijer (2001) found $t_{\text {ref }} \sim 18 \mathrm{~h}$ and $t_{\text {mix }} \sim 15 \mathrm{~h}$, respectively, whereas $t_{l} \sim 48 \mathrm{~h}$ (Meilinger et al., 2005). Similarly, in the approach proposed by Cariolle et al. (2009), the plume size and lifetime depend on the mixing properties of the atmosphere and on the threshold value $c_{\text {lim }}$ chosen for exhaust concentration. In the case of $\mathrm{NO}_{\mathrm{x}}$, this threshold is $c_{\mathrm{lim}} \sim 1 \mathrm{ppb}$ and the corresponding $t_{\mathrm{lim}} \sim 15 \mathrm{~h}$, which, again, is much lower than $t_{l}$. 


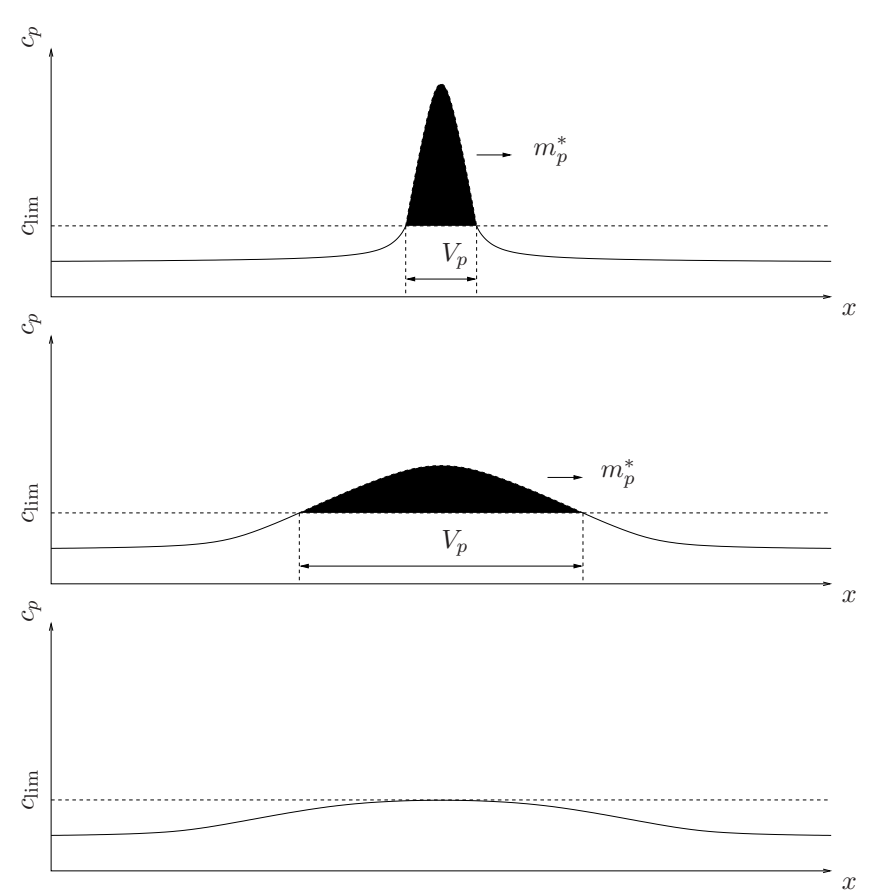

Fig. 6. Concept of plume lifetime used by Cariolle et al. (2009). Evolution of the excess of mass $m_{\mathrm{p}}^{*}$ over a threshold concentraion $c_{\text {lim }}$ of a chemically conserved species in the plume, from $t=t_{0}$ (top panel) to $t=t_{\text {lim }}$ (bottom panel). The plume lifetime $t_{\mathrm{p}}=t_{\text {lim }}$ is defined as the time when $m_{\mathrm{p}}^{*}=0$.

\section{Parameterizations of emissions into global models}

The plume models described above or explicit 3-D largeeddy simulations can represent the evolution of the plume at the different levels of sophistication. However, because of the difference of scales and representation of physical processes, it would be unrealistic to integrate all the information carried by these small-scale models into large-scale CTM. For these reasons, a number of simpler parameterizations have been developed in the literature to reconstruct a limited (but useful) number of parameters from small-scale models that can be efficiently used in CTM.

\subsection{Effective Emission Indexes (EEI)}

The concept of Effective Emission Indexes (EEI) was introduced by Petry et al. (1998) to provide corrections to instantaneous dispersion (ID) models where the emitted species are distributed instantaneously and homogeneously over the grid-box of large-scale models. Effective emissions are determined by varying the emissions obtained with ID models and by comparing the corresponding results obtained with a Single Plume model (or Multilayered plume model) at the plume lifetime $t_{\mathrm{p}} \equiv t_{\text {ref }}$ (see Eq. 26) as sketched in Fig. (8). This procedure provides the variation $\Delta c_{k}^{*}\left(t_{0}\right)$ that has to be

\section{CONCEPT of PLUME LIFETIME}
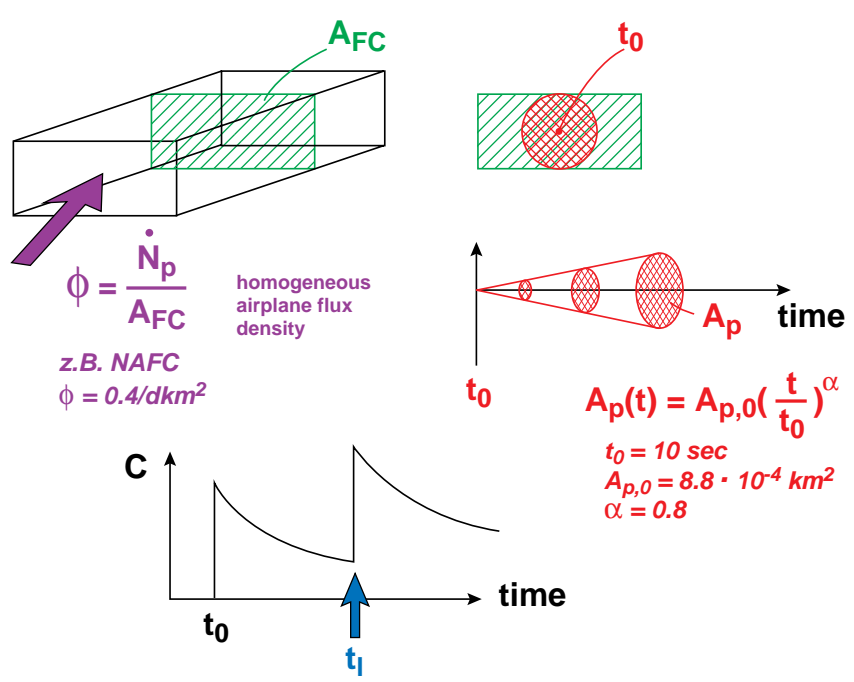

$$
\begin{gathered}
N_{P}\left(t_{I}\right) \equiv 1=\int_{t_{0}}^{t_{I}} \phi A_{p}(t) d t \Rightarrow t_{I} \begin{array}{l}
\text { plume } \\
\text { encounter time }
\end{array} \\
t_{I}=t_{0}\left(1+\frac{1+\alpha}{\phi A_{p, 0} t_{0}}\right)^{1 / 1+\alpha}
\end{gathered}
$$

Fig. 7. Schematic description of average plume encounter time, $t_{l}$ of a single aircraft in a flight corridor (Meilinger et al., 2005).

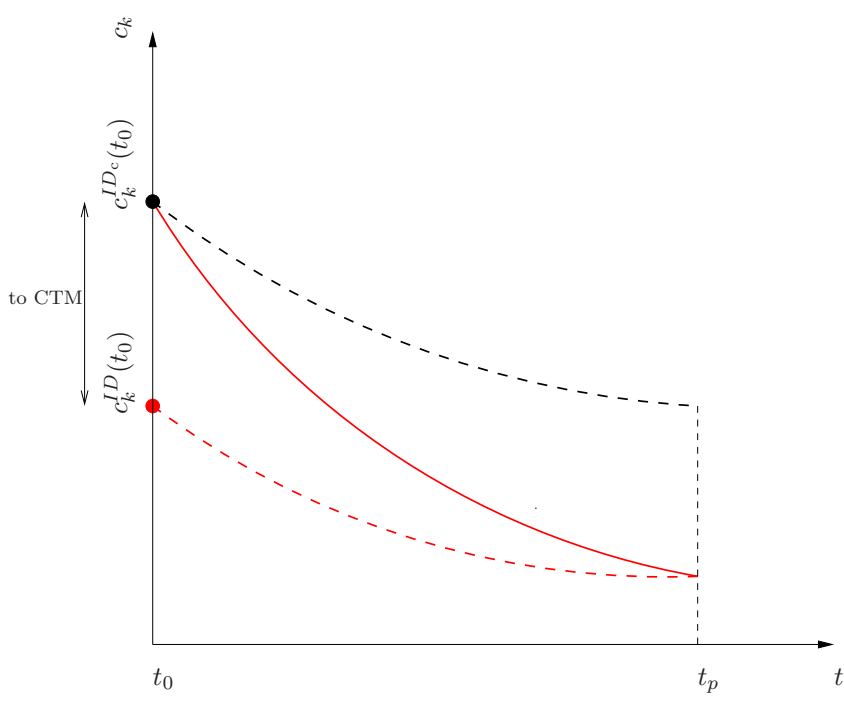

Fig. 8. Sketch of the effective emission indices (EEI) model (Petry et al., 1998). Dashed black lines: concentration evolution using the ID model with the original EI; red solid lines: concentration evolution using the SP model with the original EI; red dashed lines: concentration evolution using the ID model with the EEI.

added to the initial excess of concentration over background,

$c_{k}^{* \mathrm{ID}}\left(t_{0}\right) \equiv c_{k}^{\mathrm{p}}\left(t_{0}\right)-c_{k}^{\mathrm{a}}$ 

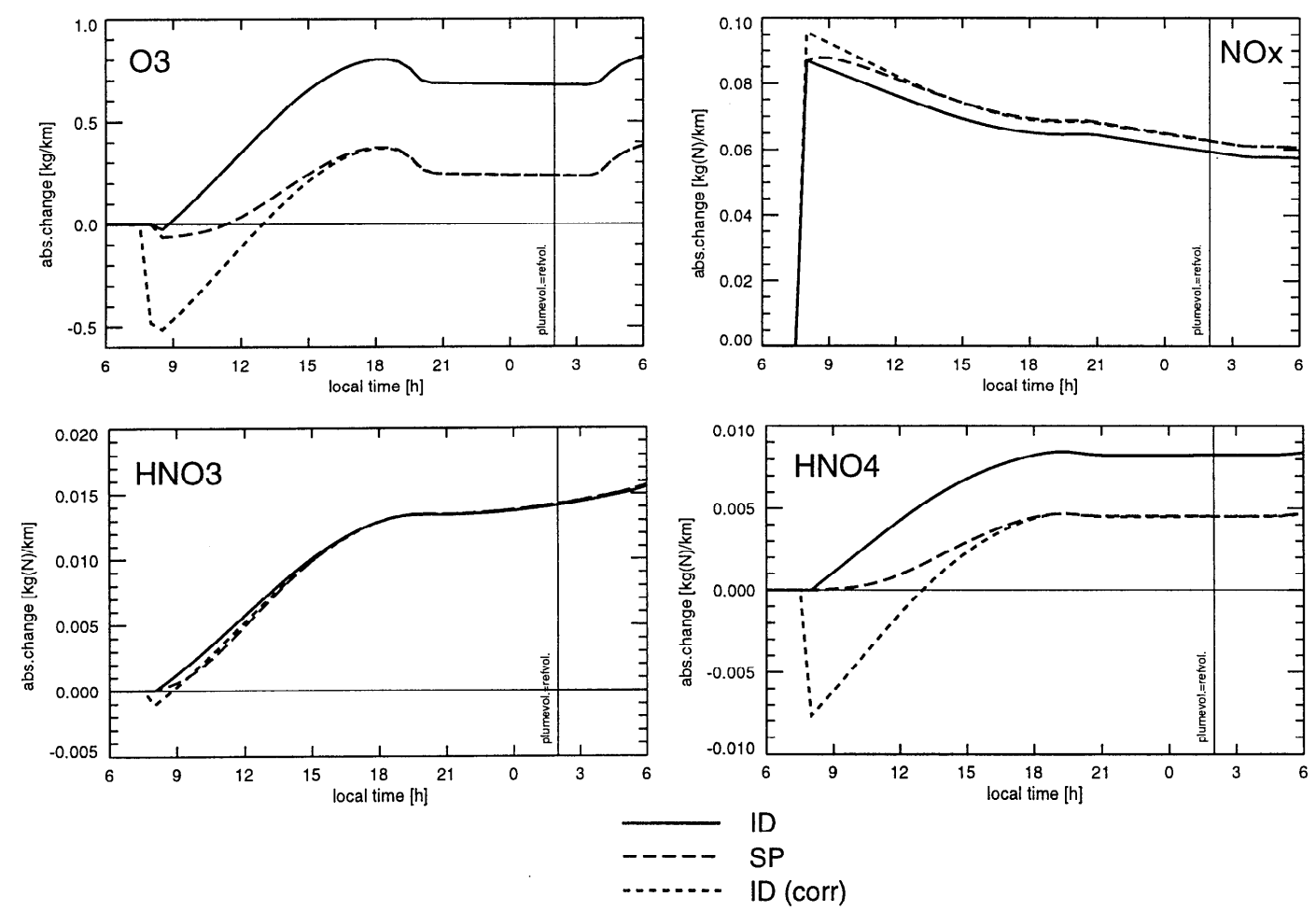

Fig. 9. Absolute changes $\left(\mathrm{kg} \mathrm{km}^{-1}\right)$ of some key species caused by emission of a B-747, released at 08:00 local time into an unpolluted atmosphere with plume lifetime is $\tau=18 \mathrm{~h}$. Reprinted from Petry et al. (1998). An edited version of this paper was published by AGU. Copyright (1998) American Geophysical Union.

to retrieve the correct value a $t=t_{\mathrm{p}}$. Once this variation is known, the initial excess of concentration $c_{k}^{* \mathrm{ID}}\left(t_{0}\right)$ is replaced by the corrected excess defined as:

$c_{k}^{* \mathrm{ID}_{\mathrm{c}}}\left(t_{0}\right)=c_{k}^{* \mathrm{ID}}\left(t_{0}\right)+\Delta c_{k}^{*}\left(t_{0}\right)$.

To guarantee the conservation of the modified nitrogen mass of emitted species like $\mathrm{NO}_{\mathrm{x}}$, an effective emission index of non-emitted or secondary species like ozone has to be introduced. Then, to obtain maximum agreement with plume model results, a minimization procedure is applied to the root mean square deviation $F$ :

$F=\sqrt{\sum_{k=1}^{N_{\mathrm{s}}}\left[\frac{c_{k}^{* \mathrm{ID}_{\mathrm{c}}}\left(t_{\mathrm{p}}\right)-c_{k}^{*}\left(t_{\mathrm{p}}\right)}{c_{k}^{*}\left(t_{\mathrm{p}}\right)}\right]^{2}}$.

For emitted species like $\mathrm{NO}_{\mathrm{x}}$, the Effective Emission Index is obtained by simply rescaling the standard Emission Index so as to take into account the correction in Eq. (36):

$\operatorname{EEI}_{k_{\mathrm{e}}}\left(t_{0}\right)=\left[1+\frac{\Delta c_{k_{\mathrm{e}}}^{*}\left(t_{0}\right)}{c_{k_{\mathrm{e}}}^{* \mathrm{ID}}\left(t_{0}\right)}\right] \mathrm{EI}_{k_{\mathrm{e}}}$.

For secondary or non-emitted species like ozone, Effective Emission Indices are defined by rescaling the $\mathrm{NO}_{\mathrm{x}}$ Emission Index as
$\mathrm{EEI}_{k_{\mathrm{ne}}}\left(t_{0}\right)=\left[\frac{W_{k_{\mathrm{ne}}}}{W_{\mathrm{NO}_{\mathrm{x}}}} \frac{\Delta c_{k_{\mathrm{ne}}}^{*}\left(t_{0}\right)}{c_{\mathrm{NO}_{\mathrm{x}}}^{* \mathrm{ID}_{0}}\left(t_{0}\right)}\right] \mathrm{EI}_{\mathrm{NO}_{\mathrm{x}}}$

where $W_{k}$ denotes the molecular weight of species $k$. Petry et al. (1998) computed the EEI by means of their Single Plume model that employs the Chemistry Module for the Lower Stratosphere and the Troposphere (CHEST). This chemical mechanism is based on the EURAD model system (Hass, 1991) and considers the transformations of 160 species by 160 homogeneous gas phase collision reactions and 26 photolysis reactions (Stockwell, 1986; Stockwell et al., 1990). Figure 9 shows a good agreement between the $c_{k}^{* \mathrm{ID}}\left(t_{\mathrm{p}}\right)$ and $c_{k}^{*}\left(t_{\mathrm{p}}\right)$ for the absolute changes of some key species, meaning that that Eq. (36) allows the concentrations of the instantaneous dispersion model to recover the correct plume model concentrations at the end of the plume lifetime. Figure 10 reports the time evolution of $\Delta c_{k}^{*}$ for different background conditions. As a general remark, Petry et al. (1998) found that the corrections to the concentration obtained with the standard ID method, can vary significantly, depending on release time and the degree pollution of the background environment. In particular, negative $\mathrm{NO}_{\mathrm{y}}$ and ozone effective emission indexes were obtained for some specific release times.

Franke et al. (2008) recently applied the EEI method to ship emissions using the plume dispersion formulation 

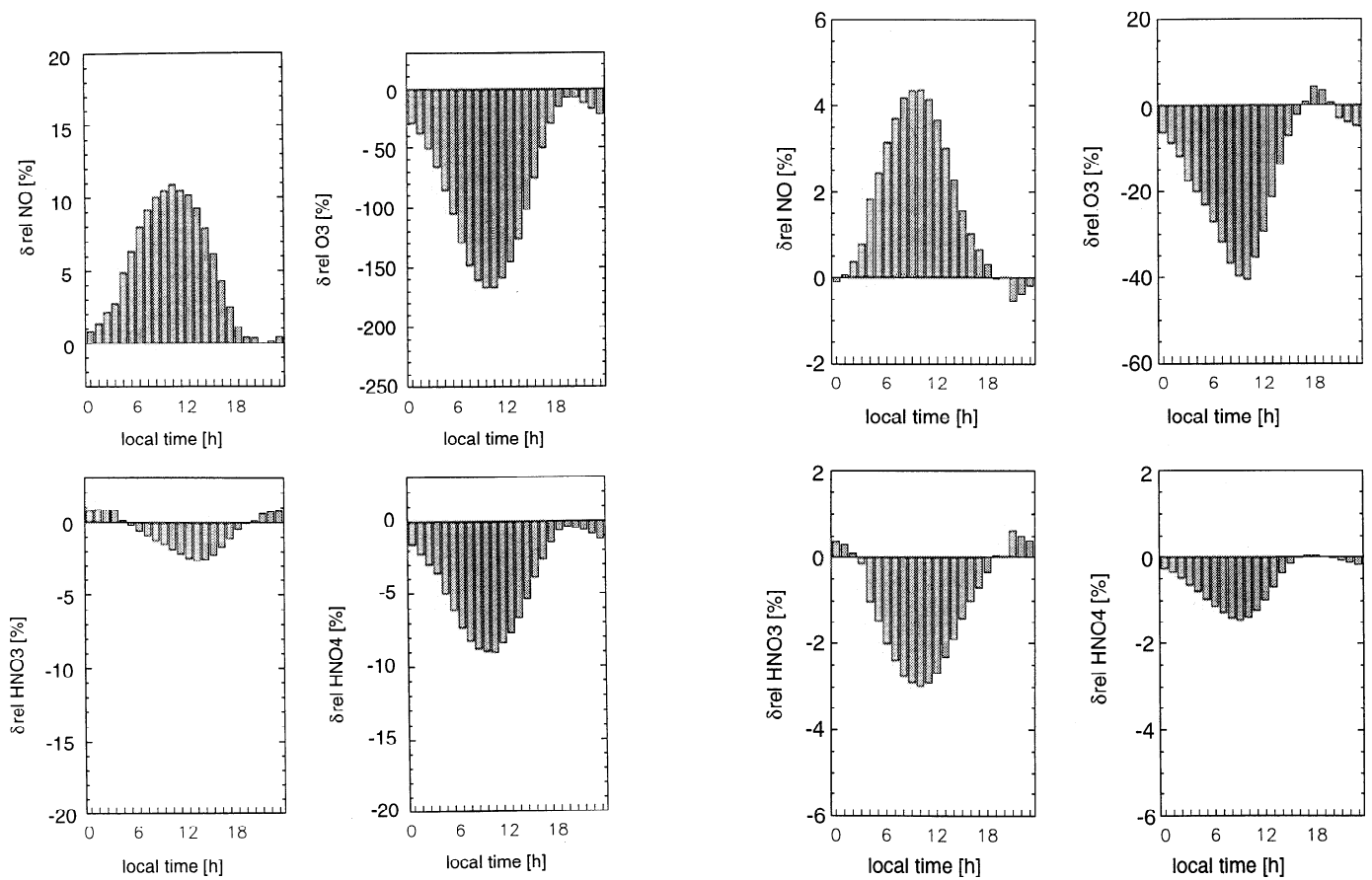

Fig. 10. Relative emission changes for calculating the effective emission indices of some key species into an unpolluted (left) and polluted (right) environment with plume lifetime is $\tau=18 \mathrm{~h}$ (Petry et al., 1998). Reprinted from Petry et al. (1998). An edited version of this paper was published by AGU. Copyright (1998) American Geophysical Union.

by Song et al. (2003b) and the photochemical box model MECCA (Sander et al., 2005), which includes 160 gas-phase reactions in addition to 116 aqueous, 61 heterogeneous and 42 equilibrium reactions for sulfur and sea-salt aerosols. Both primary emissions and secondary emissions for ozone and $\mathrm{H}_{2} \mathrm{O}_{2}$ and, in order to maintain nitrogen mass budget, the corrections of $\mathrm{NO}_{\mathrm{x}}$ were balanced by effective emissions of $\mathrm{HNO}_{3}, \mathrm{PAN}$ and sea-salt aerosol nitrate. They observed that the original $\mathrm{NO}_{\mathrm{x}}$ emissions were reduced by about $3 \%$, while ozone and $\mathrm{H}_{2} \mathrm{O}_{2}$ were, respectively, reduced by $700 \%$ and increased by $5 \%$ the amount of emitted $\mathrm{NO}_{\mathrm{x}}$ (see Fig. 11). As expected, the relative emission indexes are always negative due to the fact that they correct the ozone overestimation of the ID model box. The effective emissions of $\mathrm{O}_{3}$ are largest for release times during day and smallest during night.

Once the EEI are computed, the "effective" emissions in the CTM mass balance equations are reconstructed as

$\bar{E}_{k}^{\mathrm{eff}}=\operatorname{EEI}_{k}\left(t_{0}\right) \bar{S}_{\mathrm{f}}$.

which formally replaces Eq. (7).

\subsection{Emission Conversion Factors (ECF)}

The idea behind the method of Emission Conversion Factor (ECF) proposed by Meijer et al. (1997); Meijer (2001) is to determine the conversions of emissions (expressed in terms of excess over background) that match the values obtained from a SP model (see the sketch in Fig. 12). For emitted species, Meijer (2001) defined the excess of mass over background as the difference between the number of molecules in the control volume with and without the aircraft plume:

$m_{k_{\mathrm{e}}}^{*}(t)=V_{\mathrm{p}}(t)\left(c_{k_{\mathrm{e}}}^{p}(t)-c_{k_{\mathrm{e}}}^{a}(t)\right)$

while, for non-emitted species the excess of mass is given by

$m_{k_{\mathrm{ne}}}^{*}(t)=V_{\mathrm{p}}(t) c_{k_{\mathrm{ne}}}^{p}(t)$.

The ECF is then defined as the ratio between the emissions of species $k$ and that of all nitrogen oxides $\mathrm{NO}_{\mathrm{y}}$ (which is constant in time since $\mathrm{NO}_{\mathrm{y}}$ are chemically conserved):

$\mathrm{ECF}_{k}(t)=\frac{m_{k}^{*}(t)}{m_{\mathrm{NO}_{\mathrm{y}}}^{*}(t)}=\frac{c_{k}^{\mathrm{p}}(t)-c_{k}^{\mathrm{a}}(t)}{c_{\mathrm{NO}_{\mathrm{y}}}^{p}(t)-c_{\mathrm{NO}_{\mathrm{y}}}^{a}(t)}$

The Multilayered Plume model used to compute the ECF is described in detail in Meijer (2001). The photochemical mechanism for the troposphere contains 44 species and 103 reactions, and is adapted from Strand and Hov (1994), with gas-phase reaction rates taken from De More et al. (1997) and microphysics from Kärcher (1997). The background conditions correspond to typical values encountered along the NAFC at an altitude of about $10.5 \mathrm{~km}(250 \mathrm{hPa})$, at different times (respectively 8 a.m. and 12 a.m.) and different seasons (January and July). The ECF are reported in Fig. 13: as expected, $\mathrm{ECF}_{\mathrm{NO}_{\mathrm{x}}}$ decreases while $\mathrm{ECF}_{\mathrm{O}_{3}}$ increases as $\mathrm{NO}_{\mathrm{x}}$ is converted in the plume. For all cases, the net chemical rates 
of $\mathrm{NO}_{\mathrm{x}}$ and $\mathrm{O}_{3}$ in the plume shows large destruction rate during the first hours, whereafter the net rate slowly converges to the net rate in the ambient air (around $10 \mathrm{~h}$ ). A value of $t_{\mathrm{p}} \equiv t_{\mathrm{mix}}=15 \mathrm{~h}$ (see Eq. 27) was then suggested as a conservative choice for the plume lifetime.

A similar approach was used by Kraabøl et al. (2000b) and Kraabøl and Stordal (2000). One difference is that their chemistry scheme, taken from Kraaøbl et al. (1999), contains 66 species and 170 reactions, providing a complete description of the free-atmosphere. In addition, their analysis showed that the $\mathrm{NO}_{\mathrm{x}}$ conversion rates were most sensitive to the diurnal, seasonal and latitudinal variations of background conditions (see e.g. Fig. 14), and then suggested that such variations should be taken into account in the integration in global models. Vohralik et al. (2008) recently tested the ECF technique and confirmed the strong dependence of $\mathrm{NO}_{\mathrm{x}}$ conversion into $\mathrm{NO}_{\mathrm{y}}$ on altitude, latitude and seasonal variations (see Fig. 15).

The "effective" emissions $\bar{E}_{k}^{\text {eff }}$ in the CTM mass balance equations are reconstructed by rescaling the emissions by the ECF evaluated at the plume lifetime $t_{\mathrm{p}}$ :

$\bar{E}_{k}^{\mathrm{eff}}=\mathrm{ECF}_{k}\left(t_{\mathrm{p}}\right) \bar{E}_{k}$

\subsection{Plume Transformation Indices (PTI) and Effective Perturbation Indices (EPI)}

In the methodology proposed by Karol et al. (2000) the effective emission index is decomposed in two factors: the usual emission index that quantifies the in-engine processes (EI) and the dimensionless Plume Transformation Index (PTI):

$\mathrm{EEI}_{k}=\mathrm{EI}_{k} \times \mathrm{PTI}_{k}$

This method follows the idea of Petry et al. (1998) of modifying the emission indices but it represents the variation of the total mass (or the number of molecules) of species integrated over the entire plume lifetime rather than evaluated at $t_{\mathrm{p}}$ as in the ECF method by Meijer (2001). Subtracting Eq. (14) from Eq. (13) and integrating over $t_{\mathrm{p}}$ yields after some algebra to:

$$
\begin{aligned}
\Delta m_{k}^{*}\left(t_{\mathrm{p}}\right) & =\int_{t_{0}}^{t_{\mathrm{p}}} V_{\mathrm{p}}(t)\left[\omega_{k}^{\mathrm{p}}(t)-\omega_{k}^{\mathrm{a}}(t)\right] d t \\
& =m_{k}^{*}\left(t_{\mathrm{p}}\right)-m_{k}^{*}\left(t_{0}\right)
\end{aligned}
$$

where Eq. (41) has been used. For emitted species $k_{\mathrm{e}}$ the PTI is defined as

$\operatorname{PTI}_{k_{\mathrm{e}}}\left(t_{0}, t_{\mathrm{p}}\right)=\frac{V_{\mathrm{p}}\left(t_{0}\right) c_{k_{\mathrm{e}}}^{p}\left(t_{0}\right)+\Delta m_{k_{\mathrm{e}}}^{*}\left(t_{\mathrm{p}}\right)}{V_{\mathrm{p}}\left(t_{0}\right) c_{k_{\mathrm{e}}}^{p}\left(t_{0}\right)}$

while for species $k_{\text {ne }}$ not emitted by the aircraft and originating in plume from interaction with the emitted species $k_{\mathrm{e}}$, the PTI is given by

$\mathrm{PTI}_{k_{\mathrm{ne}}}\left(t_{0}, t_{\mathrm{p}}\right)=\frac{m_{k_{\mathrm{ne}}}^{*}\left(t_{\mathrm{p}}\right)}{V_{\mathrm{p}}\left(t_{0}\right) c_{k_{\mathrm{ne}}}^{p}\left(t_{0}\right)}$
The plume model developed by Karol et al. (1997) was used to get the $\mathrm{PTI}_{k}$. The chemistry scheme included 85 gas phase reactions and 33 compounds without heterogeneous chemistry. The plume simulations took place in the $9-12 \mathrm{~km}$ layer at $50^{\circ}$ and $30^{\circ} \mathrm{N}$ in the upper troposphere and lower stratosphere inside and outside the NAFC, in January and July. The calculations of PTI confirmed the conclusions given by Meijer et al. (1997) and Petry et al. (1998) that a significant part of $\mathrm{NO}_{\mathrm{x}}$ components emitted by subsonic aircraft may be transformed into the $\mathrm{NO}_{\mathrm{y}}$ components in the plume stage, and that these transformations are mostly sensitive to ambient air composition (see for example Fig. 16). In particular, Karol et al. (2000) observed that flying in the warm stratosphere and out of flight corridor should reduce the released $\mathrm{NO}_{\mathrm{x}}$ entering into large-scale and global reservoir of the aircraft $\mathrm{NO}_{\mathrm{y}}$.

Meilinger et al. (2005) developed a detailed plume model to analyze the microphysical processes and heterogeneous chemistry in aircraft plumes, including the formation of persitent contrails. For emitted species, they used the definition of PTI in Eq. (47) while for non emitted species, they introduced a slightly different definition, named Effective Perturbation Index:

$\mathrm{EPI}_{k_{\mathrm{ne}}}=\frac{c_{k_{\mathrm{ne}}}^{\mathrm{p}}\left(t_{l}\right)-c_{k_{\mathrm{ne}}}^{\mathrm{a}}\left(t_{l}\right)}{c_{k_{\mathrm{ne}}}^{\mathrm{a}}\left(t_{l}\right)}$

where $t_{l}$ is the average plume encounter time in the NAFC (see Sect. 3.2.1). The simulations confirmed the high sensitivity of $\mathrm{NO}_{\mathrm{x}}$ conversion and ozone formation/depletion on meteorological conditions, including relative humidity which affects the persistence of contrails (see Fig. 17).

The "effective" emissions $\bar{E}_{k}^{\text {eff }}$ in the CTM mass balance equations are reconstructed using Eqs. (7), (45) and (47)(48)

$\bar{E}_{k}^{\text {eff }}=\mathrm{EI}_{k} \mathrm{PTI}_{k}\left(t_{0}, t_{\mathrm{p}}\right) \bar{S}_{\mathrm{f}}$.

\subsection{Effective Reaction Rates (ERR)}

The method of effective reaction rates (ERR) was introduced by Cariolle et al. (2009) to study the impact of $\mathrm{NO}_{\mathrm{x}}$ emissions on the atmospheric ozone. The basic idea of the method is that the chemical transformations in the plume proceed with different rates than in the background atmosphere because of the high concentrations of exhausts within the plume. It is then possible to define "effective" reaction rate constants working on the fraction of the emissions within the plume (undiluted fraction). To discriminate between diluted and undiluted fractions of emissions, an additional transport equation for a fuel tracer is solved by the CTM:

$\frac{D \bar{C}_{\mathrm{f}}}{D t}=\bar{S}_{\mathrm{f}}-\frac{\bar{C}_{\mathrm{f}}}{\tau}$

where the last term in the right-hand side is a model for the (large-scale) fuel dilution. The decay time $\tau$ is 


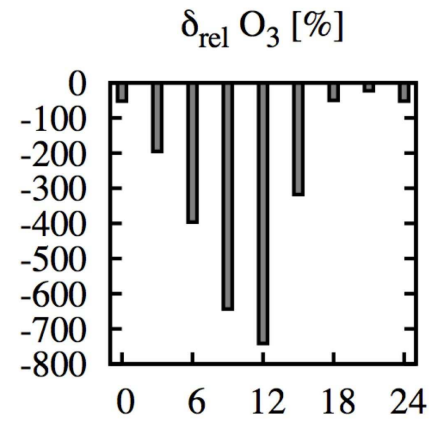

Time of Emission [LT]

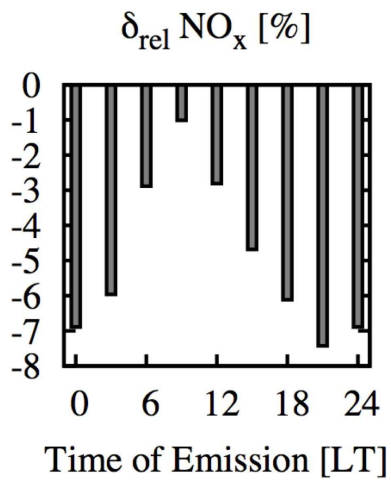

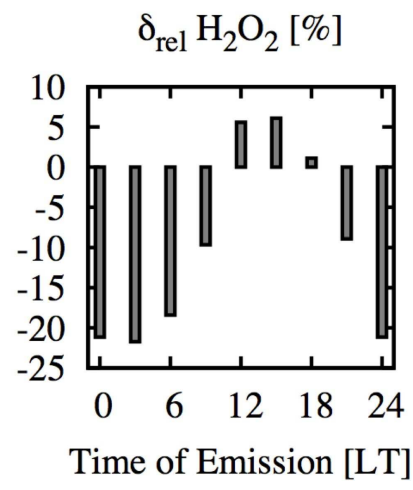

Fig. 11. Corrections of key species emissions (relative to $\mathrm{NO}_{\mathrm{x}}$ emissions) for the calcultion of EEI from ships (Franke et al., 2008).

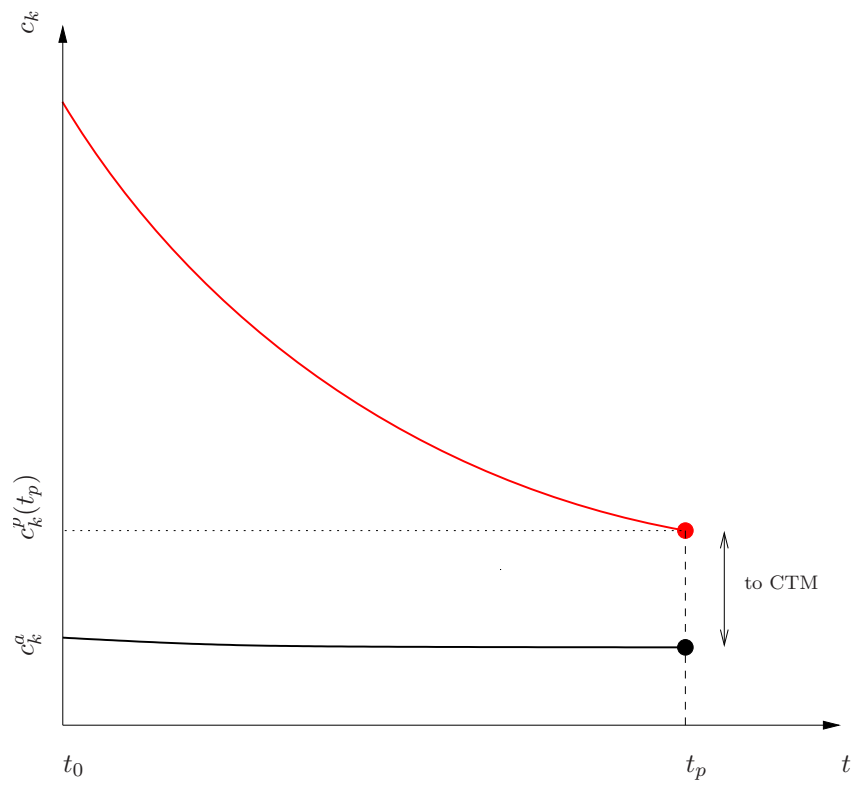

Fig. 12. Sketch of the emission conversion factor (ECF) model.

obtained by approximating the evolution of excess of exhaust mass $m_{\mathrm{p}}^{*}$ in Eq. (30) by an exponential fit: $m_{\mathrm{p}}^{*}(t)=$ $m_{\mathrm{p}}^{*}\left(t_{0}\right) \exp \left(-\left(t-t_{0}\right) / \tau\right)$ so that

$\tau \equiv \int_{t_{0}}^{+\infty} \mathrm{e}^{-\left(t-t_{0}\right) / \tau} d t=\frac{1}{m_{\mathrm{p}}^{*}\left(t_{0}\right)} \int_{t_{0}}^{t_{\mathrm{p}}} m_{\mathrm{p}}^{*}(t) d t$

where $t_{\mathrm{p}}=t_{\text {lim }}$ is defined according to the threshold value $c_{\mathrm{lim}}$ as explained in Sect. 3.2.1. The (grid-averaged) undiluted fraction of $\mathrm{NO}_{\mathrm{x}}$ (exhaust $\mathrm{NO}_{\mathrm{x}}$ ) is reconstructed using $\bar{C}_{\mathrm{f}}$ as

$\bar{C}_{\mathrm{NO}_{\mathrm{x}}}^{\mathrm{p}}=\alpha_{\mathrm{NO}_{\mathrm{x}}} \mathrm{EI}_{\mathrm{NO}_{\mathrm{x}}} \bar{C}_{\mathrm{f}}$

where $\alpha_{\mathrm{NO}_{\mathrm{x}}}=10^{-3} W_{\text {air }} / W_{\mathrm{NO}_{\mathrm{x}}}$ is a scaling factor with $W_{\text {air }}$ and $W_{\mathrm{NO}_{\mathrm{x}}}$ the molecular weights of air and $\mathrm{NO}_{\mathrm{x}}$, respectively.
To account for the effects of highly concentrated exhaust $\mathrm{NO}_{\mathrm{x}}$ on ozone concentration, an "effective" reaction rate is introduced as:

$$
\bar{K}_{\mathrm{NO}_{\mathrm{x}} \mathrm{O}_{3}}^{\mathrm{eff}}=\frac{\int_{t_{0}}^{t_{\mathrm{p}}}\left(\int_{V_{\mathrm{p}}} K_{\mathrm{NO}_{\mathrm{x}} \mathrm{O}_{3}} c_{\mathrm{NO}_{\mathrm{x}}} c_{\mathrm{O}_{3}} d V_{\mathrm{p}}\right) d t}{c_{\mathrm{O}_{3}}^{a} \int_{t_{0}}^{t_{\mathrm{p}}}\left(\int_{V_{\mathrm{p}}} c_{\mathrm{NO}_{\mathrm{x}}} d V_{\mathrm{p}}\right) d t}
$$

where the plume concentrations can be obtained using any of the plume models introduced in Sect. 3 or explicit threedimensional LES. The ozone balance equation in the CTM is modified by adding a term which represents the destruction of ozone by $\mathrm{NO}_{\mathrm{x}}$ at the scale of the grid-box and proceeds at the rate $\bar{K}_{\mathrm{NO}_{\mathrm{x}} \mathrm{O}_{3}}^{\text {eff }}$ :

$$
\frac{D \bar{C}_{\mathrm{O}_{3}}}{D t}=\bar{\omega}_{\mathrm{O}_{3}}\left(\bar{C}_{1}, . ., \bar{C}_{N_{\mathrm{s}}}\right)-\bar{K}_{\mathrm{NO}_{\mathrm{x}} \mathrm{O}_{3}}^{\mathrm{eff}} \bar{C}_{\mathrm{NO}_{\mathrm{x}}}^{p} \bar{C}_{O_{3}} .
$$

This actual implementation of ERR method to $\mathrm{NO}_{\mathrm{x}}-\mathrm{O}_{3}$ chemistry is slightly different from the general formulation of effective reactions introduced in Eq. (11) in the sense that $\bar{K}_{\mathrm{NO}_{\mathrm{x}} \mathrm{O}_{3}}^{\text {eff }}$ is constructed in such a way that the grid-averaged undiluted fraction $\bar{C}_{\mathrm{NO}_{\mathrm{x}}}^{\mathrm{p}}$ rather than the total grid-averaged concentration $\bar{C}_{\mathrm{NO}_{\mathrm{x}}}$ appear explicitly in the ozone balance equation. The ERR method gives a framework that is fully conservative for the injected species, and that relaxes to ID model when $\tau \rightarrow 0$. It was found that the $\mathrm{NO}_{\mathrm{x}}$-ozone chemistry inside the plume is characterized by a first regime during which $\mathrm{NO}$ and $\mathrm{NO}_{2}$ get to equilibrium while ozone decreases by titration of $\mathrm{NO}_{2}$, and by a following slower decrease of odd oxygen $\mathrm{NO}_{2}+\mathrm{O}_{3}$ species (see Fig. 18). Cariolle et al. (2009) further discuss the determination of $\overline{K_{\mathrm{NO}_{\mathrm{x}} \mathrm{O}_{3}}^{\mathrm{eff}}}$ for ozone and the values of $t_{\lim }$ and $\tau$, and introduce additional terms to account for $\mathrm{O}_{3}$ titration and the formation of nitric acid during the plume dilution. 

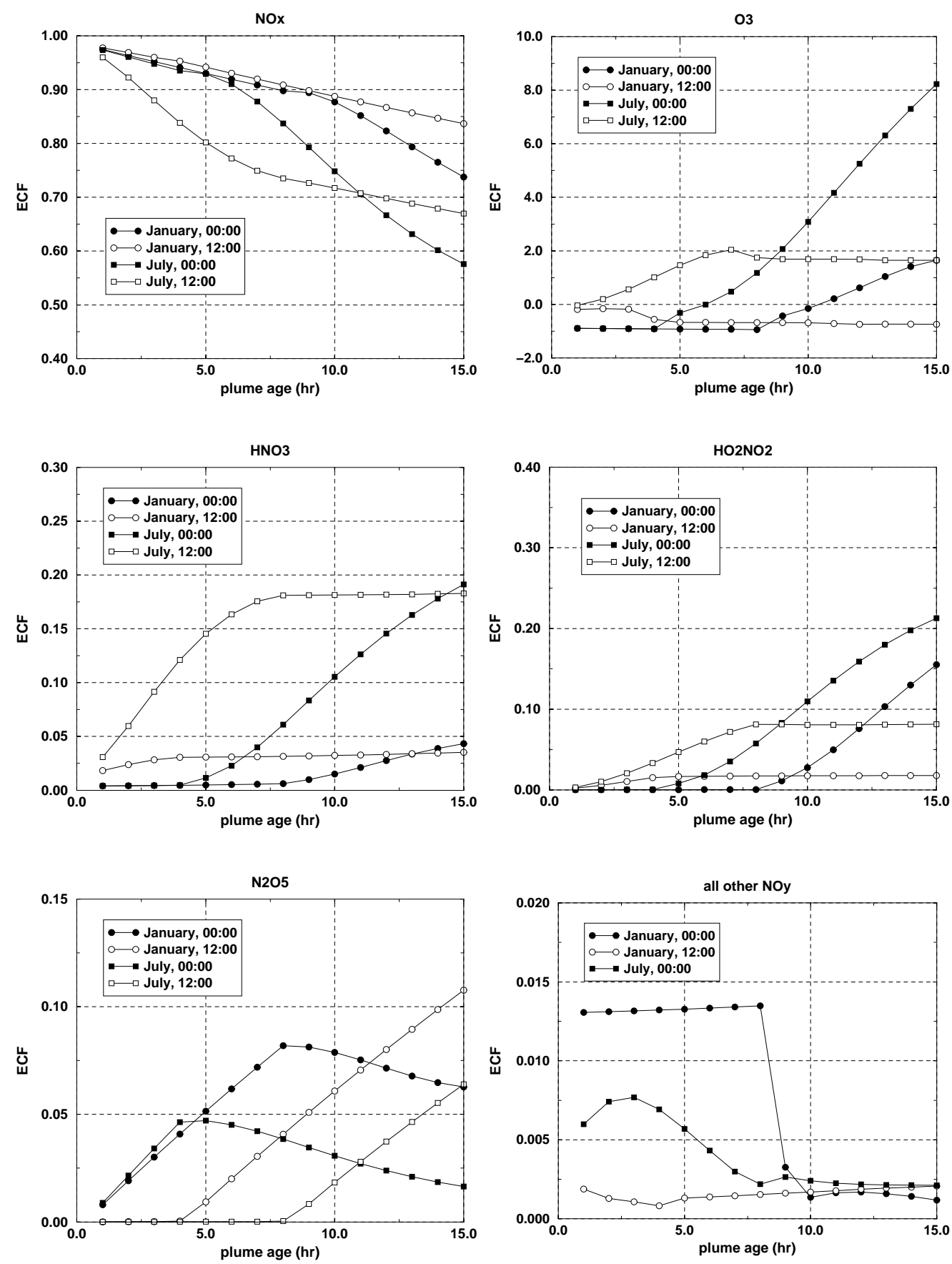

Fig. 13. Time series of emission conversion factors for some key species at different emission times (Meijer, 2001).

\section{Integration of emission parameterizations into global models}

This section describes the results of the implementation of the different parameterizations presented in Sect. 4 into global and regional models. In order to evaluate the effects of plume processes, three baseline computations can be designed:

- run A: with the unmodified emission inventories for $\mathrm{NO}_{\mathrm{x}}$ and other exhaust species
- run B: with the modified emissions $\bar{E}_{k}^{\text {eff }}$ or reaction rates $\bar{K}_{j}^{\text {eff }}$

- run $\mathrm{C}$ : without emissions

The perturbations due to the chemical conversions are then quantified in absolute numbers:

$\varepsilon_{k}=\bar{C}_{k}($ run A $)-\bar{C}_{k}($ run B $)$ 


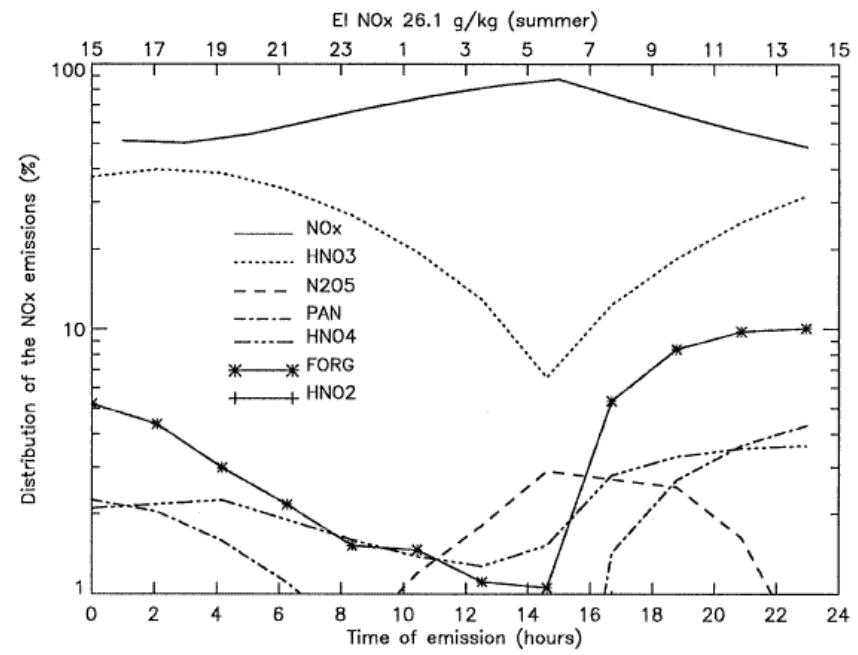

Fig. 14. Distribution of the $\mathrm{NO}_{\mathrm{x}}$ emissions after $15 \mathrm{~h}$ as a function of emission time for a summer situation at $50^{\circ} \mathrm{N}$. The upper axis gives the time after $\tau=15 \mathrm{~h}$ of integration. $\mathrm{FORG}=\mathrm{CH}_{3} \mathrm{O}_{2} \mathrm{NO}_{2}+\mathrm{CH}_{3} \mathrm{ONO}_{2}+\mathrm{C}_{2} \mathrm{H}_{5} \mathrm{ONO}_{2}+\mathrm{C}_{4} \mathrm{H}_{9} \mathrm{ONO}_{2}$ and is the sum of the oxy- and peroxynitrates included in the kinetic scheme. Reprinted from Kraabøl et al. (2000b), Atmospheric Environment, Copyright (2000), with permission.

and relative numbers:

$\varepsilon_{k \%}=\frac{\bar{C}_{k}(\operatorname{run} \mathrm{A})-\bar{C}_{k}(\operatorname{run~B})}{\bar{C}_{k}(\operatorname{run~B})-\bar{C}_{k}(\operatorname{run} C)} \times 100$.

\subsection{Application of ECF and EEI}

The ECF were first implemented by Meijer et al. (1997) in the Chemistry Transport Model CTMK (Velders et al., 1994; Wauben et al., 1997) and successively by Meijer (2001) in the TM3 model (Meijer et al., 2000). The original engine exit emissions from the DLR/ANCAT $2 \mathrm{NO}_{\mathrm{x}}$ emissions (Gardner et al., 1997) were transformed into aircraft plume emissions using the ECF in Eq. (44) at each computational cell. The plume lifetime was taken $t_{\mathrm{p}}=15 \mathrm{~h}$ (Meijer, 2001).

Figure 19 shows the monthly mean of absolute and relative $\mathrm{NO}_{\mathrm{x}}$ and $\mathrm{O}_{3}$ perturbations. As expected, the main $\mathrm{NO}_{\mathrm{x}}$ perturbations were along the main aircraft routes, with mean values of 50-100 pptv in January, and 50-110 pptv in July in the case of unmodified ANCAT emissions. The $\mathrm{O}_{3}$ perturbations around and in the main flight corridors were in the range of $1.8-2.1 \mathrm{ppbv}$ for January and $2-3.8 \mathrm{ppbv}$ for July. When the ECF parameterization was included $\mathrm{NO}_{\mathrm{x}}$ perturbations were reduced by $15-30$ pptv in January, and by 10 35 pptv in July (in relative numbers, these reductions amount to $20-30 \%$ and $20-40 \%$, respectively). Generally, the ozone perturbation is reduced due to the efficient conversion of $\mathrm{NO}_{\mathrm{x}}$ in the aircraft plumes, leading to a diminished $\mathrm{O}_{3}$ production on the global scale. On the other hand, the photochemistry in the aircraft exhaust plumes generally produces ozone. If photochemical activity is sufficiently high, net ozone production in the aircraft plumes can be large enough to enhance
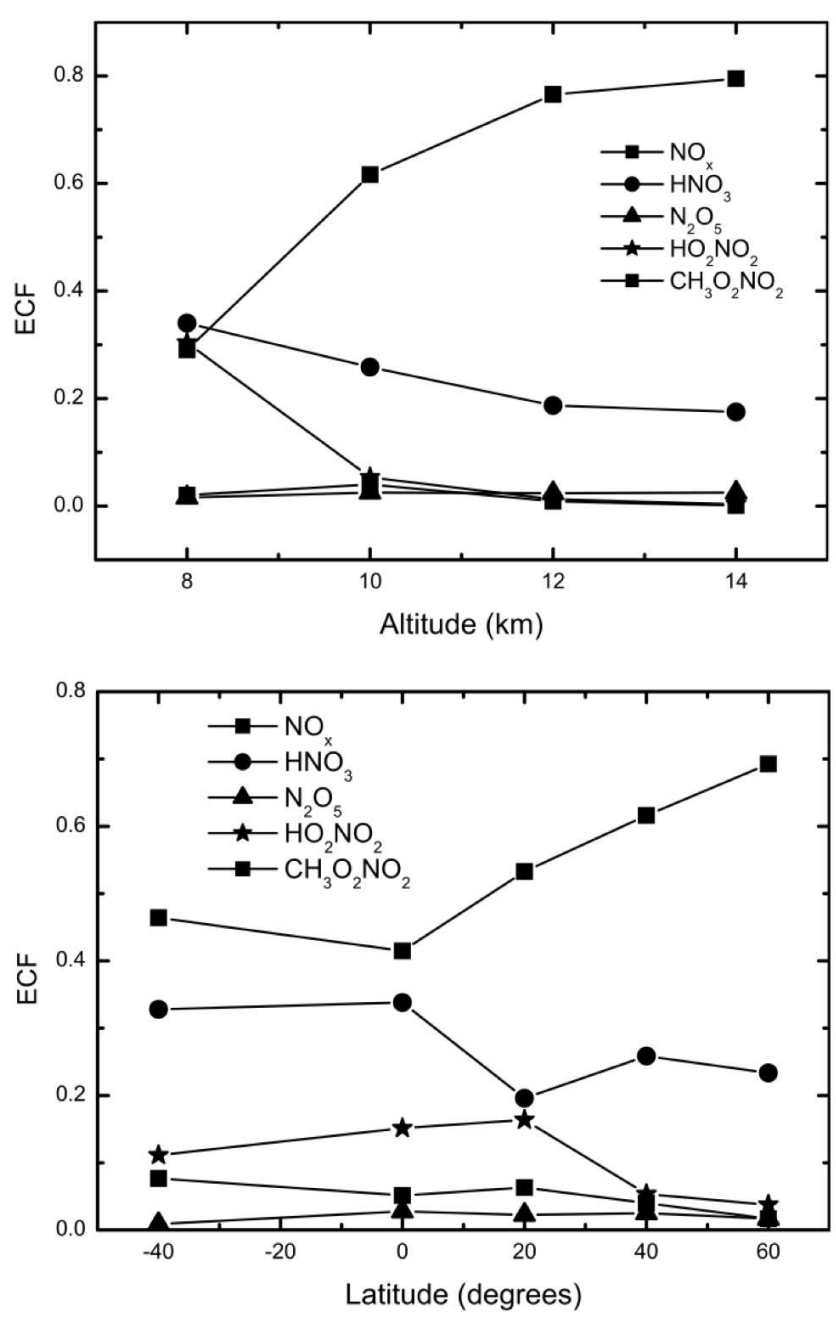

Fig. 15. Emission Conversion Factors for $\mathrm{NO}_{\mathrm{y}}$ species $24 \mathrm{~h}$ after emission (emission time 08:00 LT) as functions of altitude (top panel) and latitude (bottom panel). Reprinted from Vohralik et al. (2008). An edited version of this paper was published by AGU. Copyright (2008) American Geophysical Union.

the aircraft-induced ozone perturbation. This explains the increase (negative reduction) of the local perturbation of ozone in the NAFC for July. The maximal enhancement was $8 \%$ (note that the results presented by Meijer (2001) are slightly different from those of Meijer et al. (1997) because the net ozone production and the time of emission had not been taken into account).

Kraabøl et al. (2000a) implemented the ECF methodology into NILU-CTM, a three-dimensional chemistry transport meso-scale model covering Europe, North America, and the North Atlantic (Flatøy et al., 1995; Simpson, 1992; Strand and Hov, 1994). The spatial distribution of aircraft $\mathrm{NO}_{\mathrm{x}}$ emissions were taken from the DLR/ANCAT 2 (Gardner et al., 1997). The plume lifetime for the implementation of ECF was taken $t_{\mathrm{p}}=15 \mathrm{~h}$, which, in this case, also corresponds to a plume width of approximately the size of the computational cell. Without plume modifications, the 

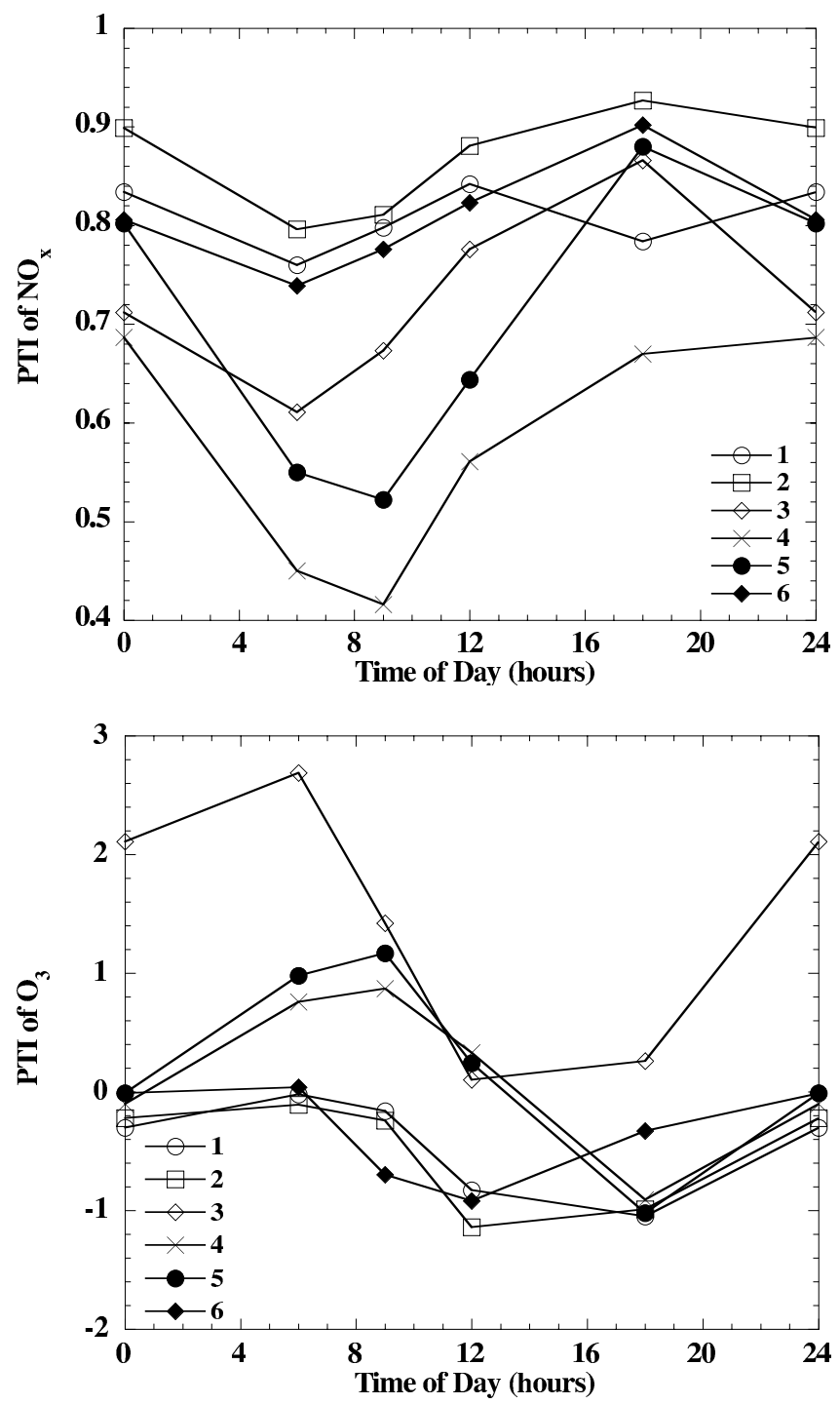

Fig. 16. Diurnal variations of $\mathrm{PTI}_{\mathrm{NO}_{\mathrm{x}}}$ (top panel) and $\mathrm{PTI}_{\mathrm{O}_{3}}$ (bottom panel) in July at $50^{\circ} \mathrm{N}$ for different conditions: 1: lower stratosphere, inside NAFC, $T=222 \mathrm{~K}, P$ plume; 2: upper troposphere, inside NAFC, $T=222 \mathrm{~K}, P$ plume; 3 : upper troposphere, outside NAFC, $T=222 \mathrm{~K}, P$ plume; 4 : lower stratosphere, inside NAFC, $T=233 \mathrm{~K}, P$ plume; 5: upper troposphere, inside NAFC, $T=233 \mathrm{~K}, P$ plume; 6 : upper troposphere, inside NAFC, $T=233 \mathrm{~K}, S$ plume. Reprinted from Karol et al. (2000). An edited version of this paper was published by AGU. Copyright (2000) American Geophysical Union.

monthly averaged increases for July for $\mathrm{NO}_{\mathrm{x}}$ and ozone were up to $70 \mathrm{ppt}$ and $2.7 \mathrm{ppb}$, respectively. On the other hand, with plume modifications, the corresponding $\mathrm{NO}_{\mathrm{x}}$ and ozone increases were reduced by $30 \mathrm{ppt}(\sim 40 \%)$ and $0.5 \mathrm{ppb}$ $(\sim 20 \%)$, respectively (see Fig. 20 ). The ozone increase within the North Atlantic Flight Corridor (NAFC) was also reduced by up to $0.5 \mathrm{ppb}(\sim 30 \%)$.
Kraabøl et al. (2002) implemented the plume model into the OSLO-CTM2 (Sundet, 1997), which is based on the chemical scheme described by Hesstvedt et al. (1978) and Berntsen and Isaksen (1999). The implementation of ECF is very similar to that used by Kraabøl et al. (2000a), expect that the variations in the turbulent conditions of the atmosphere were taken into account: following Dürbeck and Gerz (1996), the diffusivities needed by the plume model, Eqs. (15)-(17), where reconstructed in each computational cell using the probability density function of Brunt-Väisälä frequency $N$ and vertical wind shear $s$ from the ECMWF forecast data in the northern hemisphere between 8 and $12 \mathrm{~km}$. Furthermore, the plume was followed until either the size was considered large enough to be representative for the grid resolution of OSLO-CTM2 or the $\mathrm{NO}_{\mathrm{x}}$ emissions were homogeneously mixed with the surrounding air, i.e. $t_{\mathrm{p}}=\operatorname{MIN}\left(t_{\mathrm{ref}}, t_{\mathrm{mix}}\right)$, see Eq. (28) (a value of $48 \mathrm{~h}$ was taken as an upper limit).

When plume modifications with variable turbulence are included in the global model, the aircraft-induced $\mathrm{NO}_{\mathrm{x}}$ and ozone increases in the NAFC and over Europe were reduced (see Fig. 21). The absolute (relative) reductions were strongest in April/May, where $\mathrm{NO}_{\mathrm{x}}$ and ozone decreased by 15 to $25 \mathrm{pptv}$ (25-35\%) and 0.8 to $1 \mathrm{ppbv}(15-18 \%)$ at northern midlatitudes, respectively. The corresponding numbers were estimated to 8 to $22 \mathrm{ppt}(20 \%)$ for $\mathrm{NO}_{\mathrm{x}}$ and 0.4 to $0.6 \mathrm{ppb}(15-20 \%)$ for ozone in January. Kraabøl et al. (2002) finally pointed out a few issues on the modeling of $\mathrm{ECF}$ of $\mathrm{NO}_{\mathrm{x}}$ that deserve further investigation. The first issue concerns the assumption of stationary turbulence during the plume lifetime: for certain (weak) values of $N$ and $s$ from ECMWF data, this may overestimate the dispersion time of the plume to reach the resolved scale of the global model. In real atmosphere, the plume is likely to encounter conditions that favor much higher dispersion over that period. In this case the ozone production efficiency will be higher than that predicted by the simulations. The second issue is that the emissions were represented as a single plume, whereas in reality, the emissions within a computational cell of a CTM consist of multiple plumes. Mixing of multiple plumes causes a lower fraction of the emitted $\mathrm{NO}_{\mathrm{x}}$ to be converted into $\mathrm{NO}_{\mathrm{y}}$ in the plume (Kraabøl et al., 2002). Thus, more $\mathrm{NO}_{\mathrm{x}}$ will remain as $\mathrm{NO}_{\mathrm{x}}$ when the plume reaches the resolved scale of the CTM. This will lead to a higher ozone production efficiency of emissions.

The EEI and ECF techniques were recently tested by Vohralik et al. (2008) using the same plume model and the CSIRO two-dimensional chemical transport model (Randeniya et al., 2002). The comparison between the two techniques showed significant differences in the predicted $\mathrm{NO}_{\mathrm{x}}$ increase although the aircraft-induced ozone perturbations were found relatively small. In general, the predicted effects on the global impact of ozone were comparable in magnitude to those found by Meijer (2001) but considerably smaller than those obtained by Kraabøl et al. (2002). 

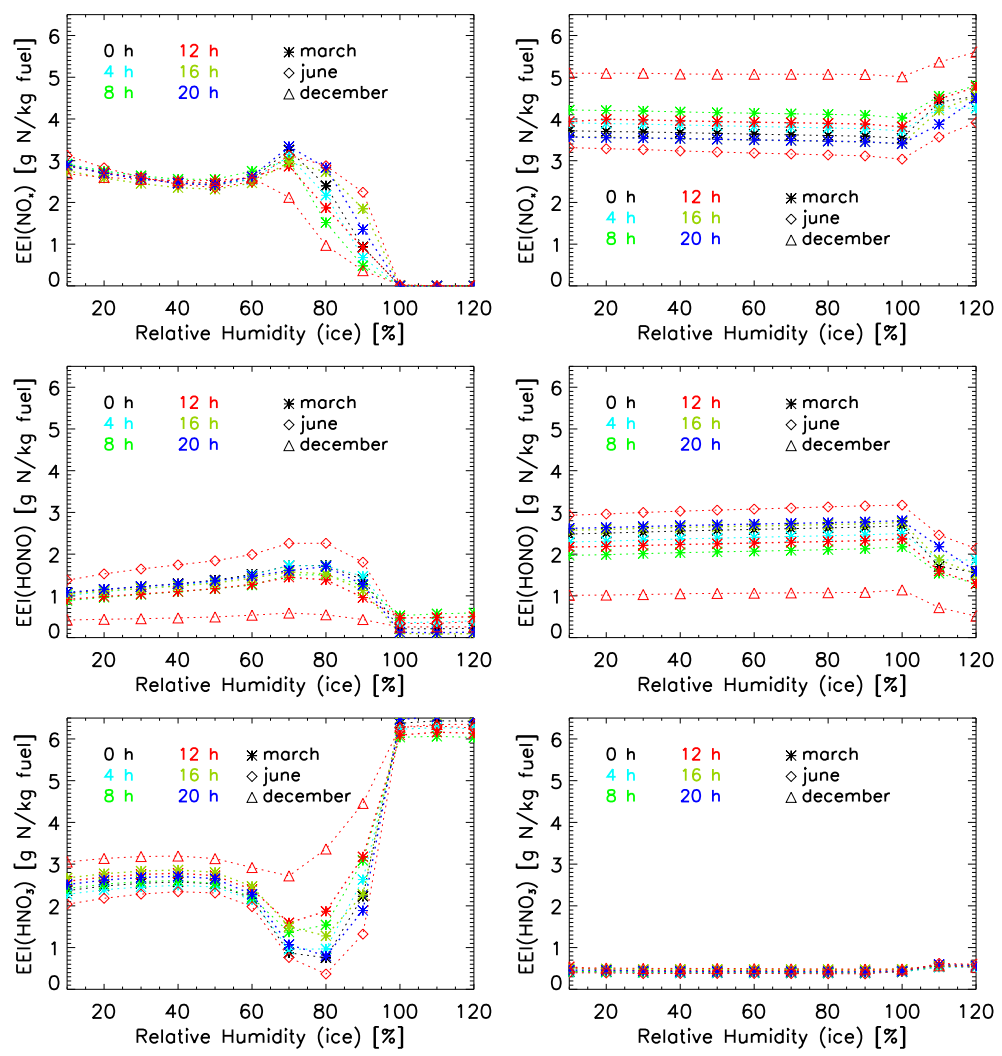

Fig. 17. Plume Transformation Indices for the NAFC $\left(t_{l}=46 \mathrm{~h}\right)$ as a function of $\mathrm{RH}_{\mathrm{ice}}$. Top panel: $\mathrm{EEI}_{\mathrm{NO}_{\mathrm{x}}}$; middle panel: EEI $\mathrm{HONO}_{\text {; }}$ lower panel: $\mathrm{EEI}_{\mathrm{HNO}_{3}}$. The different colors and symbols show results for different local times and seasons of emission as indicated. Left: emissions into the lowermost stratosphere; right: emissions into the upper troposphere (Meilinger et al., 2005).

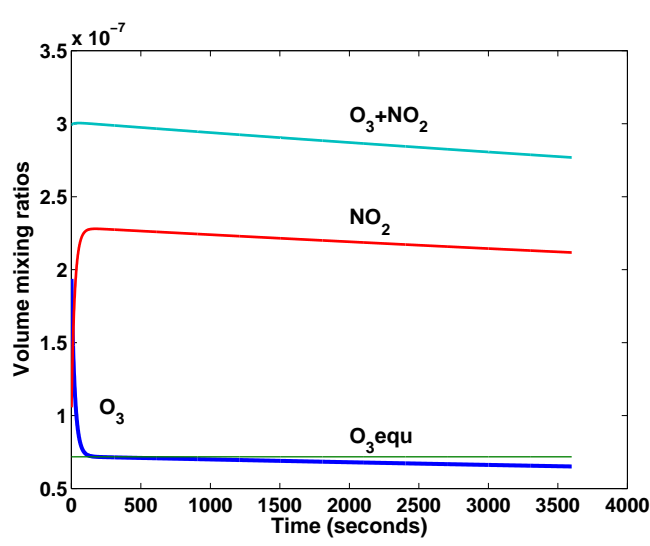

Fig. 18. Evolution of the mixing ratios of $\mathrm{NO}_{\mathrm{x}}$ and $\mathrm{O}_{3}$ after injection of $1 \mathrm{ppmv}$ of $\mathrm{NO}_{\mathrm{x}}$ at $200 \mathrm{hPa}$ (initial conditions for the simulation: $0.2 \mathrm{ppmv}$ for $\mathrm{O}_{3}$ and $T=230 \mathrm{~K}$ ). The $\mathrm{O}_{3}$ concentration decreases rapidly due to titration by $\mathrm{NO}_{2}$. The odd oxygen species $\left(\mathrm{O}_{3}+\mathrm{NO}_{2}\right)$ show a slower continuous decrease. Reprinted from Cariolle et al. (2009). An edited version of this paper was published by AGU. Copyright (2009) American Geophysical Union.

\subsection{Application of ERR}

The ERR method (Cariolle et al., 2009) has been implemented in the 3-D model LMDz-INCA (Hauglustaine et al., 2004; Folberth et al., 2006) coupled to the AERO2K emission database (Eyers et al., 2004). Figure 22 shows that the large-scale $\mathrm{NO}_{\mathrm{x}}$ content decreases significantly over the main flight corridors due to their storage in highconcentration plume form and to the conversion of a fraction of the $\mathrm{NO}_{\mathrm{x}}$ into $\mathrm{HNO}_{3}$. This large scale $\mathrm{NO}_{\mathrm{x}}$ decrease reduces the background $\mathrm{O}_{3}$ production that adds to the direct local $\mathrm{O}_{3}$ destruction found within the plume air masses. The result is a reduction of the global aircraft induced $\mathrm{O}_{3}$ production by about $15 \%$ in the northern hemisphere when the plume effects are taken into account. This result is consistent with the evaluations made using the EEI and ECF methods.

The ERR method has been recently adapted by Huszar et al. (2010) to treat the case of $\mathrm{NO}_{\mathrm{x}}$ emissions by ships within the near Atlantic European Corridor. The simulations were carried out using the CAMX, an Eulerian photochemical dispersion model developed by ENVIRON Int. Corp. (http://www.camx.com) coupled to the UN- 

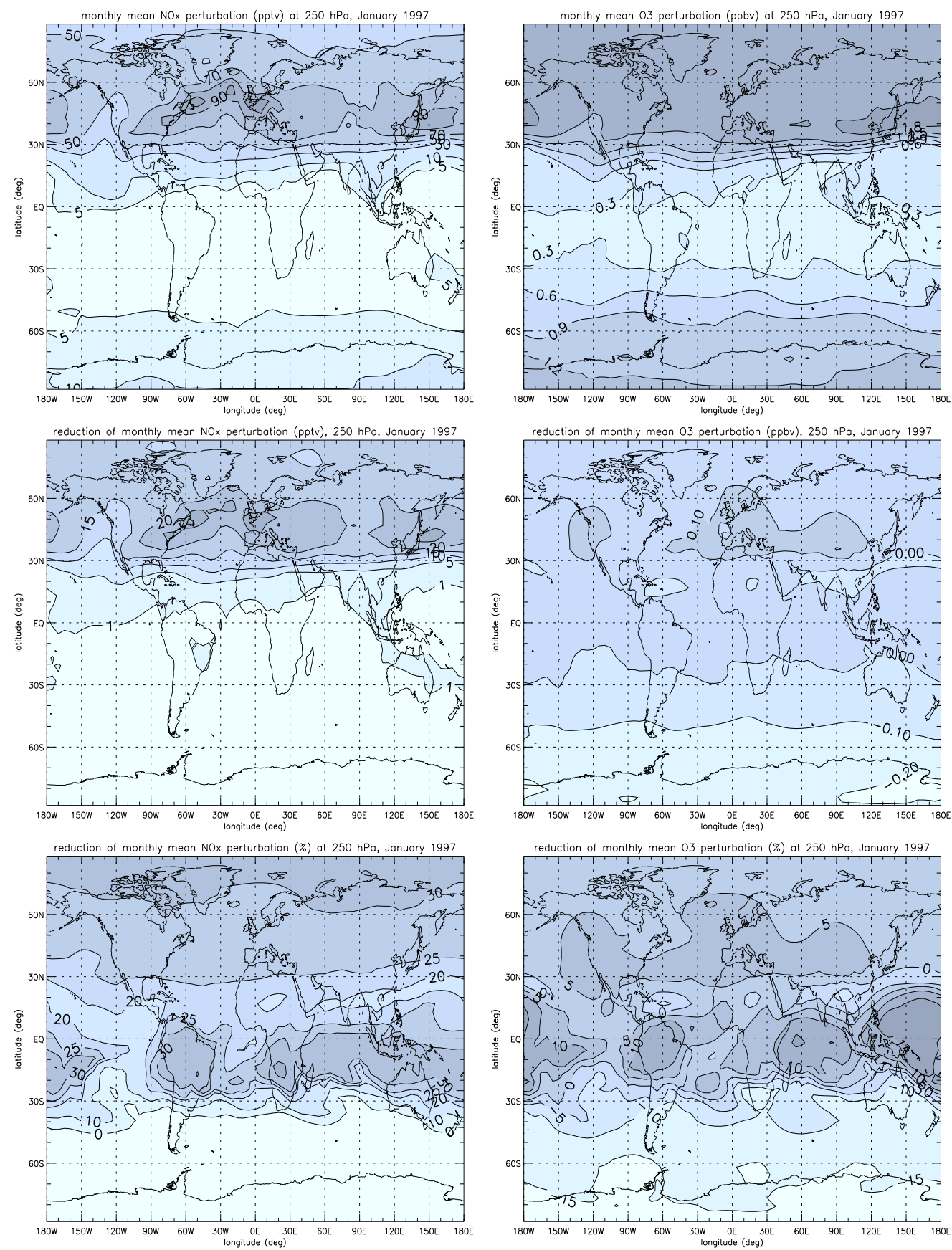

Fig. 19. Impact of aircraft $\mathrm{NO}_{\mathrm{x}}$ on the monthly mean concentration of $\mathrm{NO}_{\mathrm{x}}$ and $\mathrm{O}_{3}$ at $250 \mathrm{hPa}$ for January. Top panels, aircraft perturbations with no plume model (run $A$ ); middle panels, perturbations using ECFs (run $B$ ); bottom panels, percentage difference. Positive numbers in the lower four panels indicate a reduction due to the inclusion of aircraft plume emissions (Meijer, 2001).

ECE/EMEP emission database for year 2003 (Vestreng et al., 2007). Model results show that the ship traffic emissions strongly modify $\mathrm{NO}_{\mathrm{x}}$ levels not only over remote ocean but also at coastal areas and to some extent over land at greater distances from the sea. Highest levels of 4-6 ppbv are found over the English Channel during both seasons with peaks up to $8 \mathrm{ppbv}$ in summer. With the inclusion of the ERR plume parameterization (with $t_{\mathrm{p}}=1 \mathrm{~h}$ ), the average surface largescale $\mathrm{NO}_{\mathrm{x}}$ concentration decreases by up to $0.1 \mathrm{ppbv}$ over remote sea during both seasons. The reduction in the main corridors is much more intensive and exceeds $1 \mathrm{ppbv}$ at peak levels in both summer and winter (see Fig. 23). This can be also interpreted as the modification of the $\mathrm{NO}_{\mathrm{x}}$ perturbation caused by ship emissions. In relative numbers, model 

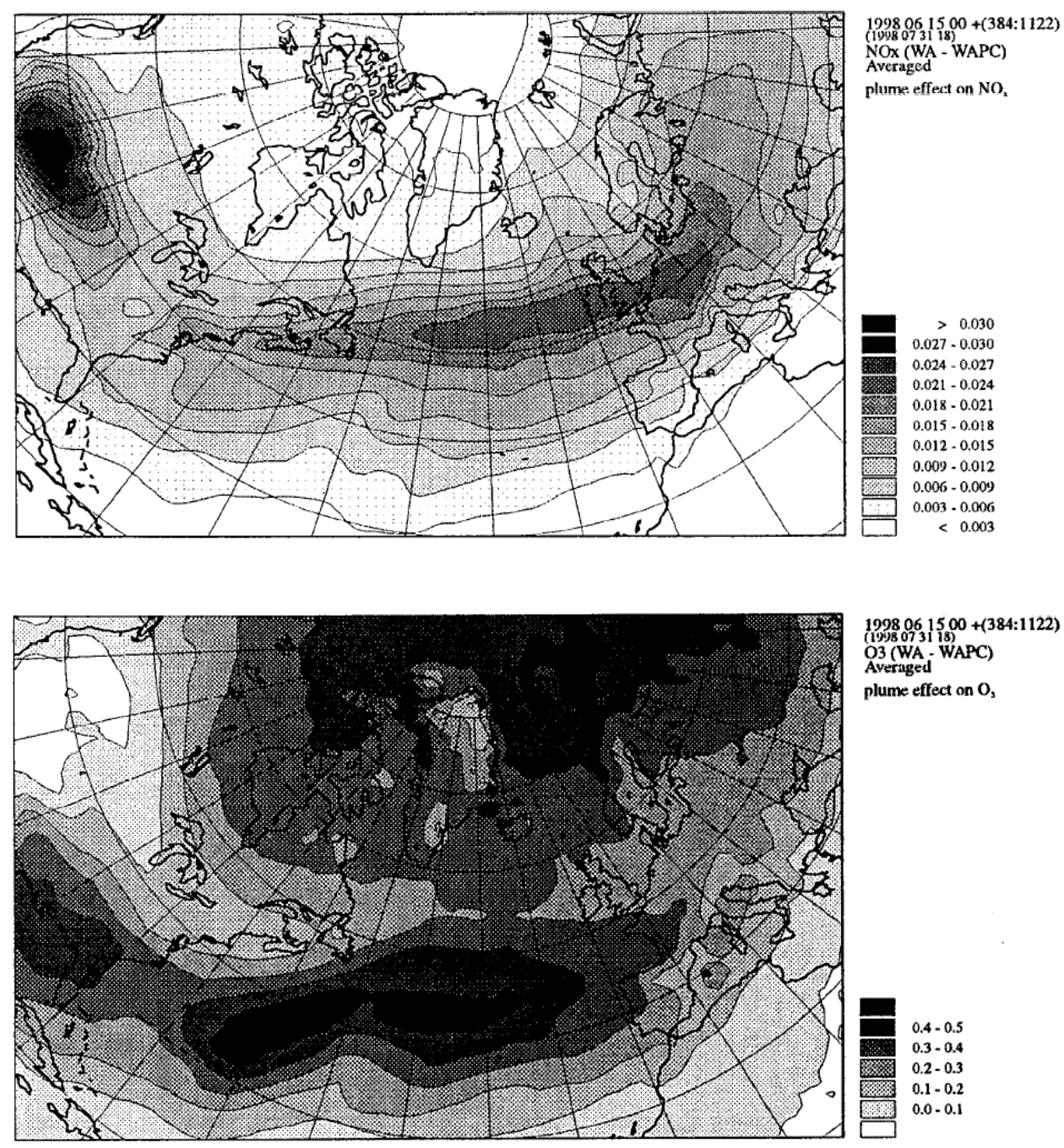

Fig. 20. Reduction in the aircraft contribution to $\mathrm{NO}_{\mathrm{x}}$ (top) and ozone (bottom) due to plume processes in the NAFC. All numbers are in $\mathrm{ppb}$. The results shown are from level four, counting from the $100 \mathrm{hPa}$ model top, $\sigma$-coordinates are used and the height of the level equals $215 \mathrm{hPa}$ when the ground pressure is $1000 \mathrm{hPa}$. Reprintedfrom Kraabøl et al. (2000a). An edited version of this paper was published by AGU. Copyright (2000) American Geophysical Union.

simulations show that ship $\mathrm{NO}_{\mathrm{x}}$ perturbation is reduced by more than $10 \%$ along shipping routes. Areas of intensive ship traffic (coastal regions and the most important shipping corridors) indicate larger reduction up to $20-25 \%$. As a consequence, ozone production due to the ship emission is reduced. The ship plume effects lead to decrease of ozone in both summer and winter seasons. The reduction occurs on the whole area of the European domain with the largest effects in the shipping corridors where the ozone reduction reaches values of about $0.4-0.7 \mathrm{ppbv}$ in winter and $1-2 \mathrm{ppbv}$ during summer conditions.

\section{Validation and verification of plume parameterizations}

Validation. The process of validation of atmospheric models depends on the class of models considered. While in CTMs validation consists in the comparison of model results with observations corresponding to specific climatologies (e.g. Stockwell and Chipperfiled, 1999), in CCMs it is interpreted in a statistical sense as the capability of the model to reproduce past climate record (e.g. Stevenson et al., 2006) or as a process-oriented validation that spans a larger variable space (e.g. Eyring et al., 2005). The validation of effective emissions methods describe here has to be interpreted in an indirect way via the underlying sub-grid model. Indeed, because these methods are parameterizations of plume processes, it is rather the validation of plume models themselves that is 
January
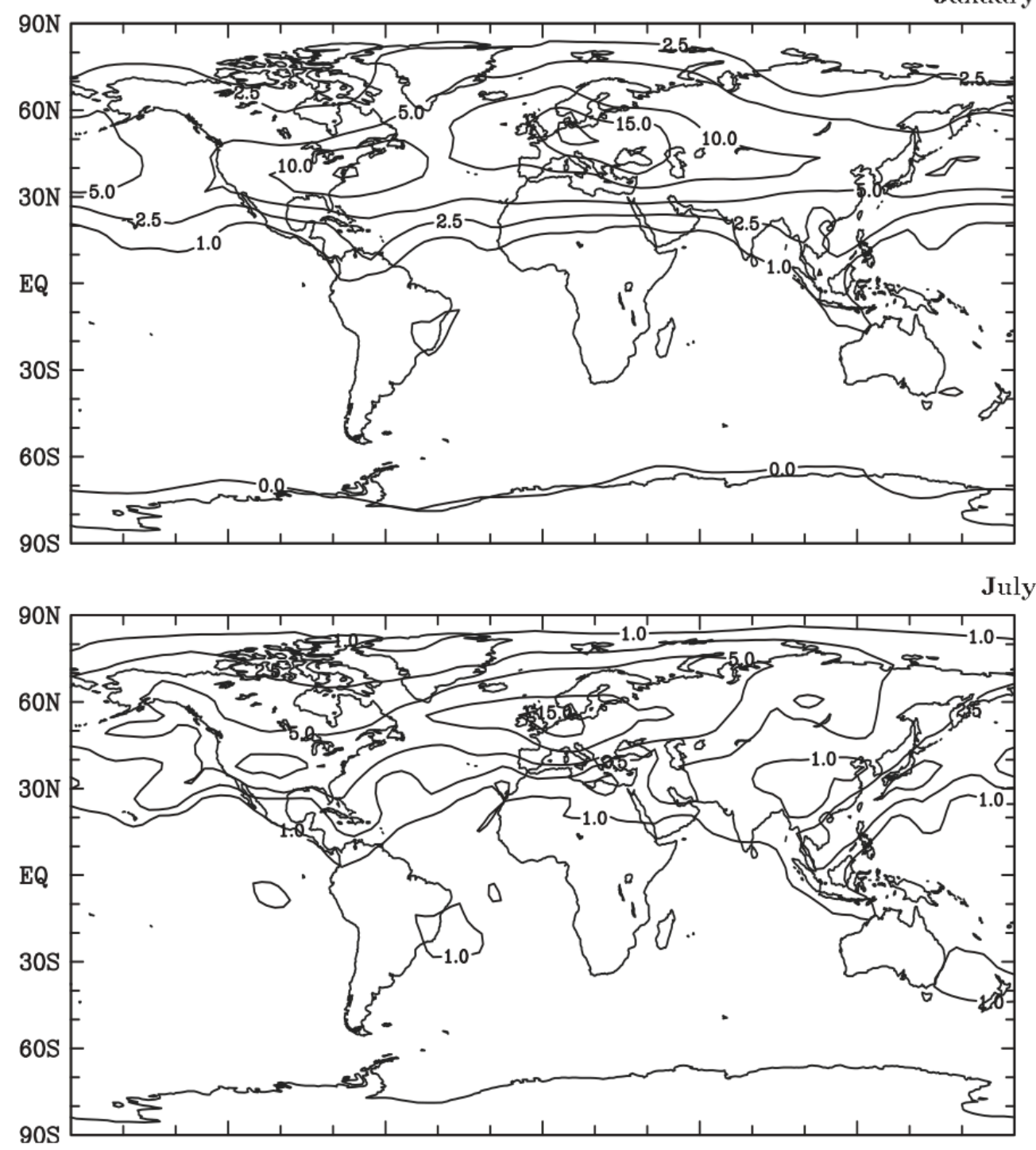

Fig. 21. Absolute decreases in aircraft-induced $\mathrm{NO}_{\mathrm{x}}$ (in pptv) in January (top) and July (bottom) at $250 \mathrm{hPa}$ due to plume effects. Reprinted from Kraabøl et al. (2002). An edited version of this paper was published by AGU. Copyright (2002) American Geophysical Union.

most pertinent. In the case of plume chemistry models, comparisons with available observation exist especially for aircraft emissions (Arnold et al., 1992; Schumann et al., 1995; Schulte et al., 1997; Schlager et al., 1997; Schumann et al., 1998). Data from Arnold et al. (1992) were used for example to validate the plume model used by Petry et al. (1998) to derive the EEI method. Similarly, for the ECF method, Kraabøl et al. (2000a) reported a fair agreement between $\mathrm{NO}_{\mathrm{x}}$ and $\mathrm{HNO}_{3}$ concentrations obtained with their model with measurements by Schulte et al. (1997) among others during the POLINAT campaign. On can claim a general confidence in the results of plume models at least for chemical processes (contrails still deserve much special care especially in the transition phase into cirrus). Consistency between plume and global models is another important point that should also be checked when deriving plume parameterizations. In particular, for effective emissions methods one has to insure that the physical models and the background conditions used in the plume model are consistent with the corresponding models and grid-box averaged quantities where the parameterizations will operate. As a general remark, it would be helpful for model validation to have more refined data in the uppertroposphere meteorological that are able to provide a detailed signature of plume. High-resolution numerical weather prediction models are complementary in this respect in that they can provide plume models with detailed local meteorological situation: this is particularly helpful for effective emissions where plume models with their built-in atmospheric parameters (shear, stability, etc.) have to be plugged into grid-boxes of global models. 
LMDz-INCA
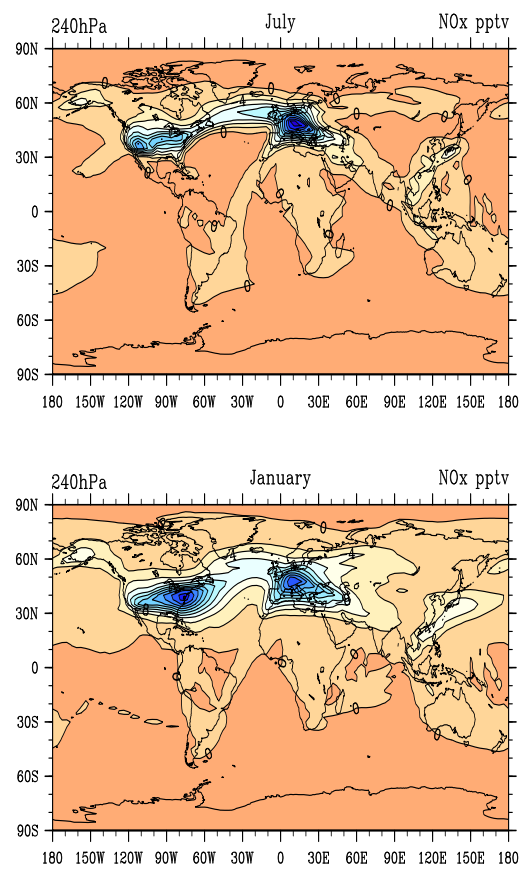

Exp. PL2-BC
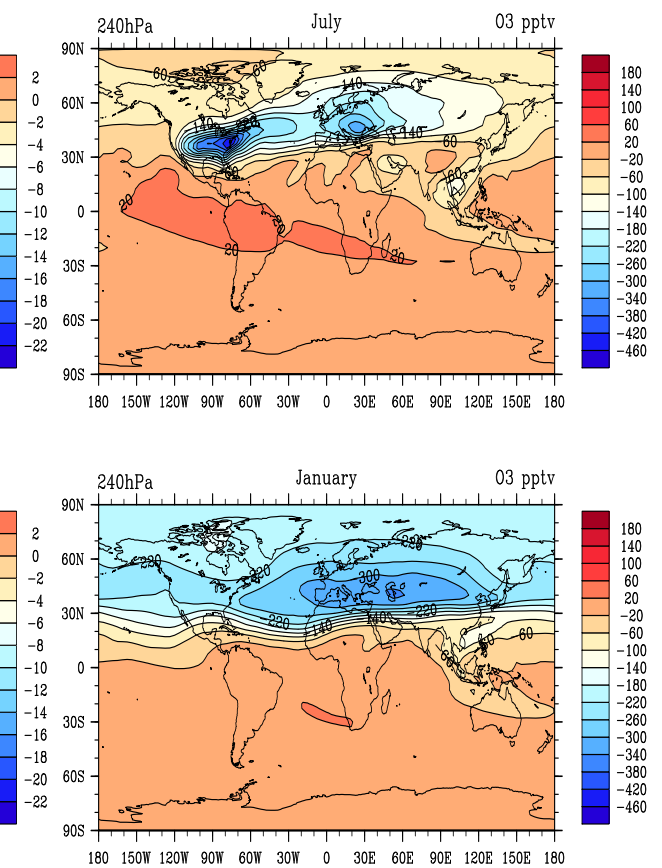

Fig. 22. LMDz-INCA model distributions of the $\mathrm{NO}_{\mathrm{x}}$ (left) and $\mathrm{O}_{3}$ (right) variations at $240 \mathrm{hPa}$ in January (bottom panels) and July (upper panels) due to plume effects using the ERR method. Reprinted from Cariolle et al. (2009). An edited version of this paper was published by AGU. Copyright (2009) American Geophysical Union.
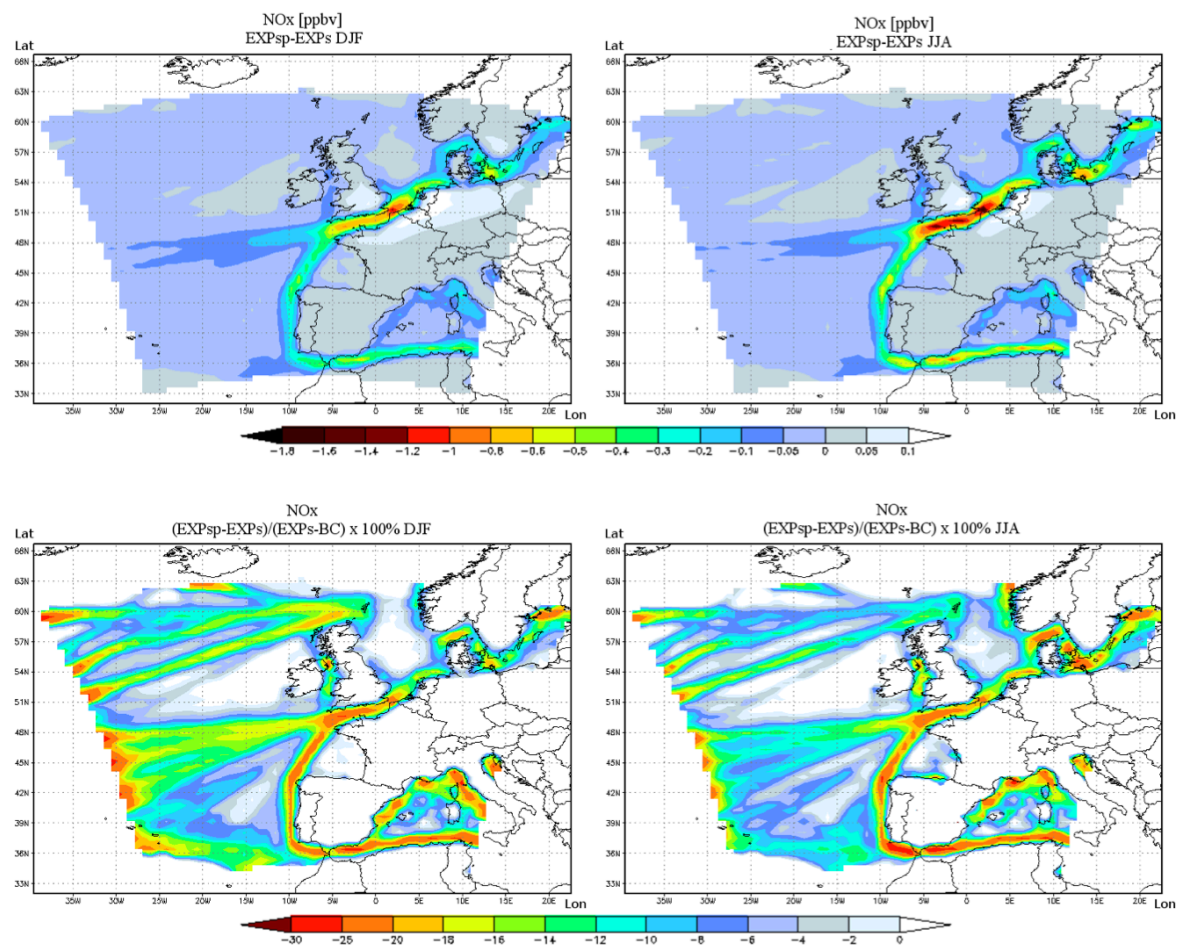

Fig. 23. Change in $\mathrm{NO}_{\mathrm{x}}$ production by ship emissions. Top panels: difference of surface $\mathrm{NO}_{\mathrm{x}}$ in experiments with and without plume model, $\varepsilon_{\mathrm{NO}_{\mathrm{x}}}$ (Eq. 56) in ppbv for winter (left) and summer conditions (right). Bottom panels: same but for relative change $\varepsilon_{\mathrm{NO}_{\mathrm{x}} \%}(\mathrm{Eq} .57)(\mathrm{Huszar}$ et al., 2010). 
Table 3. Summary of the key features of EEI, ECF and ERR methods.

\begin{tabular}{|c|c|c|c|}
\hline & EEI & $\mathrm{ECF}$ & ERR \\
\hline \multirow[t]{9}{*}{ Method } & - change $\bar{E}_{k}$ in global model Eq. (6) & - change $\bar{E}_{k}$ in global model Eq. (6) & - change $\bar{\omega}_{k}$ in global model Eq. (6) \\
\hline & & & - transport fuel tracer $\bar{C}_{\mathrm{f}}$ Eq. $(51)$ \\
\hline & & & - define undiluted $\bar{C}_{\mathrm{NO}_{\mathrm{x}}}^{\mathrm{p}}$ Eq. (53) \\
\hline & - specifies plume lifetime & - specifies plume lifetime & - specifies plume lifetime \\
\hline & - define $\mathrm{EEI}_{k}$ Eqs. (38)-(40) & - define $\mathrm{ECF}_{k}$ Eqs. (43)-(44) & - define $\bar{K}_{\mathrm{NO}_{\mathrm{x}} \mathrm{O}_{3}}^{\text {eff }}$ Eq. (54) \\
\hline & - insert $\bar{E}_{k}^{\text {eff }}=\operatorname{EEI}_{k} \bar{S}_{\mathrm{f}}$ in Eq. $(10)$ & - insert $\bar{E}_{k}^{\text {eff }}=\mathrm{ECF}_{k} \mathrm{EI}_{k} \bar{S}_{\mathrm{f}}$ & - insert $\bar{K}_{\mathrm{NO}_{\mathrm{x}} \mathrm{O}_{3}}^{\text {eff }}$ in Eq. (55), using \\
\hline & and solve for $\bar{C}_{k}$ : & in Eq. (10) and solve for $\bar{C}_{k}$ : & Eq. (53) and solve for $\bar{C}_{k}$ and $\bar{C}_{\mathrm{f}}$ : \\
\hline & $\frac{D \bar{C}_{k}}{D t}=\bar{\omega}_{k}\left(\bar{C}_{1}, \ldots, \bar{C}_{N_{\mathrm{s}}}\right)$ & $\frac{D \bar{C}_{k}}{D t}=\bar{\omega}_{k}\left(\bar{C}_{1}, . ., \bar{C}_{N_{\mathrm{s}}}\right)$ & $\frac{D \bar{C}_{\mathrm{O}_{3}}}{D t}=\bar{\omega}_{\mathrm{O}_{3}}\left(\bar{C}_{1}, . ., \bar{C}_{N_{\mathrm{s}}}\right)$ \\
\hline & $+\mathrm{EEI}_{k} \bar{S}_{\mathrm{f}}$ & $+\mathrm{ECF}_{k} \bar{S}_{\mathrm{f}}$ & $\begin{array}{l}\quad-\alpha_{\mathrm{NO}_{\mathrm{x}}} \mathrm{EI}_{\mathrm{NO}_{\mathrm{x}}} \bar{K}_{\mathrm{NO}_{\mathrm{x}} \mathrm{O}_{3}}^{\mathrm{eff}} \bar{C}_{\mathrm{f}} \bar{C}_{O_{3}} \\
\frac{D \bar{C}_{\mathrm{f}}}{D t}=\bar{S}_{\mathrm{f}}-\frac{\bar{C}_{\mathrm{f}}}{\tau}\end{array}$ \\
\hline \multirow[t]{5}{*}{ Key features } & $\begin{array}{l}-\mathrm{EEI}_{k} \text { depends on plume model } \\
\text { output (pre-computed) }\end{array}$ & $\begin{array}{l}-\mathrm{ECF}_{k} \text { depends on plume model } \\
\text { output (pre-computed) }\end{array}$ & $\begin{array}{l}-\bar{K}_{\mathrm{NO}_{\mathrm{x}} \mathrm{O}_{3}}^{\text {eff }} \text { depends on plume model } \\
\text { output (pre-computed) }\end{array}$ \\
\hline & & & $-\bar{C}_{\mathrm{f}}$ transported by the global model \\
\hline & - modifies $\mathrm{EI}_{k}$ so that the species & - modifies $\mathrm{EI}_{k}$ using species & - use fuel tracer to identify undiluted \\
\hline & excess from ID model matches that & excess normalized by $\mathrm{NO}_{\mathrm{y}}$ excess & $\mathrm{NO}_{\mathrm{x}}$ in the grid-box reacting with \\
\hline & from plume model after dilution & after plume dilution & ambient ozone via $\overline{\mathrm{NO}_{\mathrm{x}} \mathrm{O}_{3}}$ \\
\hline \multirow{7}{*}{$\begin{array}{c}\text { Strength (+) } \\
\text { Weakness (-) }\end{array}$} & (+) simplicity: no need of additional & (+) simplicity: no need of additional & $(+)$ consistency with CTM: fuel \\
\hline & transport equations & transport equations & tracer (plume) is traced at run-time \\
\hline & $(+)$ available for general emissions & $(+)$ available for general emissions & $\begin{array}{l}\text { (+) conservation automatically } \\
\text { insured (only changes CTM rates) }\end{array}$ \\
\hline & (-) consistency with CTM: need to & (-) consistency with CTM: need to & $(-)$ requires knowledge of key \\
\hline & calibrate plume excess for each run & calibrate plume excess for each run & non-linear reactions to calibrate \\
\hline & (-) chemical conservation difficult & $(-)$ care in conservation at large-scale & (-) presently developed only for \\
\hline & to insure, negative $\mathrm{EEI}_{\mathrm{O}_{3}}$ & (e.g. avoid double counting of $\mathrm{O}_{3}$ ) & $\mathrm{NO}_{\mathrm{x}}-\mathrm{O}_{3}$ chemistry \\
\hline References & Petry et al. (1998) & Meijer (2001), Kraabøl et al. (2002) & Cariolle et al. (2009) \\
\hline
\end{tabular}

Verification. Verification is another important ingredient to assess the quality of physical models and computational methods (in any area of geophysical or engineering sciences, see e.g. Roache, 1998). Generally speaking, verification is the process of determining whether the model works in a specific implementation as it has been designed for (while validation is the process of determining whether the model gives a good representation of real world). This distinction is particularly crucial to test effective emissions methods because only model verification permits to identify the error associated to these methods from the errors in the global model itself. The practical implementation of verification techniques depends on specific situations but as a general pathway, we could borrow ideas from other areas such as in the turbulence modeling community (where it is often called a posteriori testing). An instructive exercise of verification could be to set up an ideal scenario where a plume is initialized into a large computational domain (with sufficient resolution for the plume to be explicitly resolved). Species concentrations in such domain evolve according to some model equations (that we may call global model) without any sub-grid treatment of the plume. In this ideal situation and assuming the global model is exact, the model output is also exact. Then, the same model can be run again on the same domain using much lower resolution so that the plume is not explicitly resolved (as in a real CTM) but activating the sub-grid parameterizations (EEI, ECF or ERR). The volume-averaged species concentrations obtained from the latter run should then match or be close to the exact model output of the first run. Again, this exercise can only guaranty that the effective emissions method is verified, i.e. that it reproduces the correct large-scale behavior of the full global model under identical conditions. 


\section{Discussion and conclusions}

In this study we presented a summary of various methods proposed in the literature to parameterize the chemical transformations of emissions from concentrated sources into large-scale models. All the analyzed parameterizations described in the previous sections are based on a two-step procedure: first a data-set from a small-scale model is generated; then these data are transfered to the global model. The data-set can be obtained using single plume models with various levels of sophistication, or even large-eddy simulations, depending on the accuracy required to represent plume processes. However, the choice of the data that are to be transferred and the way they are incorporated in the global models vary substantially among the different parameterizations. The differences among the methods are summarized in Tab. 3 and are now briefly discussed.

In the EEI and the ECF/PTI methods, the emission rates themselves are modified, i.e. the source terms $E_{k}$ in Eq. (7) are rescaled by some factors that take into account the chemical transformations in the plume. In the EEI method, the correction is directly made at emission time by changing the original emission index EI "as if" an equivalent emission were instantaneously dispersed at large scale, see Fig. 8. On the other hand, in the ECF method the emissions are rescaled by the excess of concentrations over background at the end of the plume lifetime $t=t_{\mathrm{p}}$ as shown in Fig. 12. It is worth observing that if the large-scale transport is switched off (steady state or $D / D t=0$ ), the two methods should provide the same results at $t=t_{\mathrm{p}}$ since the species concentrations are only determined by the same plume model. Note that since the concentration emissions are changed, additional corrections are needed in both methods to insure conservation (respectively a minimization procedure, Eq. (37) in EEI method, and a re-normalization by the $\mathrm{NO}_{\mathrm{y}}$ excess in the ECF method).

In the ERR method, the reaction rates rather than the emissions themselves are modified which automatically insure conservation. In the case of secondary formed species like ozone, the use of effective reaction rates does not directly introduce pre-computed tendencies, but act as a modulation of the chemical cycles existing in the background atmosphere. Furthermore, the method takes into account the transport of pollutants during the plume dilution by explicitly solving a transport equation for fuel tracer. Thus, the non-linear chemical effects can apply rather far from the point of injection depending on the large-scale advection and the plume lifetime. This also insure that ERR relaxes to the ID model as $\tau \rightarrow 0$. Nevertheless, the ERR method still requires that some key reactions within the plume have to be identified in order to compute the relevant effective reactions.

It is worth remarking that the plume parameterizations reported in the literature and summarized here essentially focused on $\mathrm{NO}_{\mathrm{x}}$-ozone chemistry. Indeed, because of the strong non-linearity of chemical reactions due to the high
$\mathrm{NO}_{\mathrm{x}}$ plume concentration, sub-grid non-homogeneities are expected to be significant at the scale of CTM grid-boxes (which contain the plume or part of it). On the other hand, for other important emissions contributing to the Earth radiative budget like $\mathrm{CH}_{4}$ (Lee et al., 2009), the characteristic timescales of chemical reactions are much larger than plume dilution timescales, and no special special sub-grid parameterization is needed. In other words, the effects of chemical reactions involving $\mathrm{CH}_{4}$ on ozone is indirect in the sense that it can be handled by standard CTM chemistry as if $\mathrm{CH}_{4}$ were instantaneously diluted at the scale of the grid-box and react with ambient ozone.

Finally, as discussed in the previous section, the integration plume parameterizations requires that a good consistency exists between the physical processes represented in the plume and in the background atmosphere. This consistency can be easily insured for gas phase chemistry, but it is more difficult to achieve for heterogeneous processes because of the different level of complexity used to represent these processes in plume models and the 3-D largescale models. This is particularly relevant to aircraft contrails when, under specific atmospheric conditions, line-shaped contrails transform into cirrus clouds. In those cases, the microphysics used in the plume model has to be consistent with the cloud parameterization of the large-scale model. Some movements in this direction have been recently proposed in recent literature. For example, Burkhardt and Kärcher (2009) presented a parameterization of contrail cirrus in a global climate model based on the identification of contrail coverage in the grid-box. Ship emissions certainly deserves even more focus research on this aspect because of the complex interaction of gaseous $\mathrm{NO}_{\mathrm{x}}$ and $\mathrm{SO}_{\mathrm{x}}$ chemistry with aerosol and cloud microphysics in the boundary layer.

Acknowledgements. This work was supported by the European Union FP6 Integrated Project QUANTIFY (http://www.pa.op.dlr.de/quantify/) and by the RTRA-STAE project ITAAC.

Edited by: A. Stenke

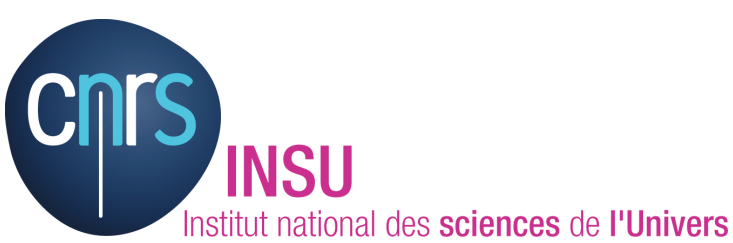

The publication of this article is financed by CNRS-INSU. 


\section{References}

Arnold, F., Scheid, J., Stilp, T., Schlager, H., and Reinhardt, M. E.: Measurements of jet engine aricraft emissions at cruise altitude, 1, the odd-nitrogen gases $\mathrm{NO}, \mathrm{NO}_{2}, \mathrm{HNO}_{2}$ and $\mathrm{HNO}_{3}$, Geophys. Res. Lett., 19, 2421-2424, 1992.

Berntsen, T. K. and Isaksen, I. S. A.: The effect of lightning and convection on changes in tropospheric ozone due to $\mathrm{NO}_{\mathrm{x}}$ emissions from aircraft, Tellus, 51B, 766-788, 1999.

Brasseur, G. P., Müller, J.-F., and Granier, C.: Atmospheric impact of $\mathrm{NO}_{\mathrm{x}}$ emissions by subsonic aircraft, J. Geophys. Res., 101, 1423-1428, 1996.

Brasseur, G. P., Cox, R. A., Hauglustaine, D., Isaksen, I., Lelieveld, J., Lister, D. H., Sausen, R., Schumann, U., Wahner, A., and Wiesen, P.: European scientific assessment of the atmospheric effects of aircraft emissions, Atmos. Environ., 32, 2329-2418, 1998.

Burkhardt, U. and Kärcher, B.: Process-based simulation of contrail cirrus in a global climate model, J. Geophys. Res., 114, D16201, doi:10.1029/2008JD011491, 2009.

Cariolle, D., Caro, D., Paoli, R., Hauglustaine, D., Cuenot, B., Cozic, A., and Paugam, R.: Parameterization of plume chemistry into large scale atmospheric models: application to aircraft $\mathrm{NO}_{\mathrm{x}}$ emissions, J. Geophys. Res., 114, D19302, doi:10.1029/2009JD011873, 2009.

Cess, R. D., Potter, G. L., Blanchet, J. P., Boer, G. J., Del, G., Deque, M., Dymnikov, V., Galin, V., Gates, W.-L., Ghan, S. J., Kiehi, J. T., Lacis, A. A., Le, T.-H., Li, Z. X., Liang, X. Z., McAvaney, B. J., Meleshko, V. P., Mitchell, J. F. B., Morcrette, J. J., Randall, D. A., Rikus, L., Roeckner, E., Royer, J.-F., Schlese, U., Sheinin, D. A., Slingo, A., Sokolov, A. P., Taylor, K. E., Washington, W. M., Wetherald, R. T., Yagai, I., and Zhange, M. H.: Intercomparison and interpretation of climate feedback processes in 19 atmospheric general circulation models, J. Geophys. Res., 95, 16601-16615, 1990.

Chosson, F., Paoli, R., and Cuenot, B.: Ship plume dispersion rates in convective boundary layers for chemistry models, Atmos. Chem. Phys., 8, 4841-4853, doi:10.5194/acp-8-4841-2008, 2008.

Corbett, J. J.: New Directions: Designing Ship Emissions and Impacts Research to Inform Both Science and Policy, Atmos. Environ., 37, 4719-4721, 2003.

Corbett, J. J. and Köhler, H. W.: Updated emissions from ocean shipping, J. Geophys. Res., 108, 4650, doi:10.1029/2003JD003751, 2003.

Danilin, Y. M., Rodriguez, J. M., Ko, M. K. W., Weisenstein, D. K., Brown, R. C., Myake-Lye, R., and Anderson, M. R.: Evolution of the concentrations of trace species in an aircraft plume: trajectory studies, J. Geophys. Res., 99, 18951-18972, 1994.

De More, W. B., Sander, S. P., Golden, D. M., Molina, M. J., Hampson, R. F., Kuyko, M. J., Howard, C. J., Ravishankara, A. R., and Kolb, C. E.: Chemical kinetics and photochemical data for use in stratospheric modeling, Evalutaion number 12, Tec. Rep. Publ. 97-4, JPL, 1997.

Dürbeck, T. and Gerz, T.: Dispersion of aircraft exhausts in the free atmosphere, J. Geophys. Res., 101, 26007-26016, 1996.

Durkee, P. A., Chartier, R. E., Brown, A., Trehubenko, E. J., Rogerson, S. D., Skupniewicz, C., Nielsen, K. E., Platnick, S., and King, M. D.: Composite ship track characteristics, J. Atmos. Sci., 57, 2542-2553, 2000.
Eyers, C. J., Norman, P., Middel, J., Plohr, M., Atkinson, K., and Christou, R. A.: AERO2k global aviation emissions inventories for 2002 and 2025, Tec. Rep. QINETIQ/04/01113, QINETIQ, available at: http://www.cate.mmu.ac.uk/reports_aero2k. asp?chg=projects\&chg\%2+2, 2004.

Eyring, V., Harris, N. R. P., Rex, M., Shepherd, T. G., Fahey, D. W., Amanatidis, G. T., Austin, J., Chipperfield, M. P., Dameris, M., de F. Foster, P. M., Gettelman, A., Graf, H. F., Nagashima, T., Newman, P. A., Pawson, S., Prather, M. J., Pyle, J. A., Salawitch, R. J., Santer, B. D., and Waugh, D. W.: A strategy for processoriented validation of coupled chemistry-climate models, Bull. Amer. Meteor. Soc., 86, 1117-1133, 2005.

Eyring, V., Stevenson, D. S., Lauer, A., Dentener, F. J., Butler, T., Collins, W. J., Ellingsen, K., Gauss, M., Hauglustaine, D. A., Isaksen, I. S. A., Lawrence, M. G., Richter, A., Rodriguez, J. M., Sanderson, M., Strahan, S. E., Sudo, K., Szopa, S., van Noije, T. P. C., and Wild, O.: Multi-model simulations of the impact of international shipping on Atmospheric Chemistry and Climate in 2000 and 2030, Atmos. Chem. Phys., 7, 757-780, doi:10.5194/acp-7-757-2007, 2007.

Eyring, V., Isaksen, I. S., Berntsen, T., Collins, W. J., Corbett, J. J., Endresen, O., Grainger, R. G., Moldanova, J., Schlager, H., and Stevenson, D. S.: Transport impacts on atmosphere and climate: Shipping, Atmos. Environ., 44, 4735-4771, 2010.

Flatøy, F., Hov, Ø., and Smit, H.: Three-dimensional model studies of exchange processes of ozone in the troposphere over Europe, J. Geophys. Res., 100, 11465-11481, 1995.

Folberth, G. A., Hauglustaine, D. A., Lathière, J., and Brocheton, F.: Interactive chemistry in the Laboratoire de Mtorologie Dynamique general circulation model: model description and impact analysis of biogenic hydrocarbons on tropospheric chemistry, Atmos. Chem. Phys., 6, 2273-2319, doi:10.5194/acp-62273-2006, 2006.

Franke, K., Eyring, V., Sander, R., Hendricks, J., Laurer, A., and Sausen, R.: Toward effective emissions of ships in global models, Meteorol. Z., 17, 117-129, 2008.

Galmarini, S., Vinuesa, J.-F., and Martilli, A.: Modeling the impact of sub-grid scale emission variability on upper-air concentration, Atmos. Chem. Phys., 8, 141-158, doi:10.5194/acp-8-141-2008, 2008.

Gardner, R. M., Adams, K., Cook, T., Deidewig, F., Ernedal, S., Falk, R., Fleuti, E., Herms, E., Johnson, C. E., Lecht, M., Lee, D. S., Leech, M., Lister, D., Massé, B., Metcalfe, M., Newton, P., Schmitt, A., Vanderbergh, C., and van Drimmelen, R.: The ANCAT/EC global inventory of $\mathrm{NO}_{\mathrm{x}}$ emissions from aircraft, Atmos. Env., 31, 1751-1756, 1997.

Gerz, T., Dürbeck, T., and Konopka, P.: Transport and effective diffusion of aircraft emissions, J. Geophys. Res., 103, 2590525914, 1998.

Hanna, S. R., Schulman, L. L., Paine, R. J., Pleim, J. E., and Baer, M.: Develpment and evaluation of the offshore and coastal dispersion model, J. Air Pollut. Control Assoc., 35, 1039-1047, 1985.

Hass, H.: Description of the EURAD Chemistry-Transport Model Version 2 (CTM2), in: Mitteilungen, edited by: Ebel, A., Neubauer, F. M., and Speth, P., Inst. for Geophys. and Meteorol., Univ. of Köln, 1991.

Hauglustaine, D. A., Hourdin, F., Jourdain, L., Filiberti, M. A., Walters, S., Lamarque, J. F., and Holland, E. A.: Interac- 
tive chemistry in the Laboratoire de Météorologie Dynamique general circulation model: description and background tropospheric chemistry evaluation, J. Geophys. Res., 109, D04314, doi:10.1029/2003JD003957, 2004.

Hesstvedt, E., Hov, Ø., and Isaksen, I. S. A.: Quasi-steady-state approximations in air pollution modelling. Comparison of two numerical schemes of oxidant prediction, Int. J. Chem. Kinetics, 10, 971-994, 1978.

Huszar, P., Cariolle, D., Paoli, R., Halenka, T., Belda, M., Schlager, H., Miksovsky, J., and Pisoft, P.: Modeling the regional impact of ship emissions on $\mathrm{NO}_{\mathrm{x}}$ and ozone levels over the Eastern Atlantic and Western Europe using ship plume parameterization, Atmos. Chem. Phys., 10, 6645-6660, doi:10.5194/acp-10-66452010, 2010.

Jaeglé, L., Jacob, D. J., Brune, W. H., Tan, D., Faloona, I. C., Weinheimer, A. J., Ridley, B. A., Campos, T. L., and Sachse, G. W.: Sources of $\mathrm{HO}_{\mathrm{x}}$ and ozone production in the upper troposphere over the United States, Geophys. Res. Lett., 24, 17091712, 1998.

Kärcher, B.: Heterogeneous chemistry in aircraft wakes: constraints for uptake coefficients, J. Geophys. Res., 102, 19119-19135, 1997.

Karol, I. L., Ozolin, Y. E., and Rozanov, E. V.: Box and Gaussian plume models of the exhaust composition evolution of subsonic transport aircraft in- and out of the flight corridor, Ann. Geophys., 15, 88-96, doi:10.1007/s00585-997-0088-0, 1997.

Karol, I. L., Ozolin, Y. E., Kiselev, A. A., and Rozanov, E. V.: Plume Transformation Index (PTI) of the subsonic aircraft exhausts and their dependence on the external conditions, Geophys. Res. Lett., 27, 373-376, 2000.

Kasibhatla, P., Levy II, H., Moxim, W. J., Pandis, S. N., Corbett, J. J., Peterson, M. C., Honrath, R. E., Frost, G. J., Knapp, K., Parrish, D. D., and Reyerson, T. B.: Do emissions from ships have a significant impact on concentrations of nitrogen oxides in the marine boundary layer?, Atmos. Environ., 37, 2663-2679, 2003.

Konopka, P.: Analytical Gaussian solutions for anisotropic diffusion in a linear shear flow, J. Non-Equilib. Thermodyn., 20, 7891, 1995.

Kraabøl, A. G. and Stordal, F.: Modelling chemistry in aircraft plumes 2: the chemical conversion of $\mathrm{NO}_{\mathrm{x}}$ to reservoir species under different conditions, Atmos. Environ., 34, 3951-3962, 2000.

Kraaøbl, A. G., Stordal, F., Konopka, P., and Knudsen, S.: The NILU aircraft plume model: a technical description, Tech. Rep. NILU TR 4/99, Norvegian Institute for Air Research, 1999.

Kraabøl, A. G., Flatøy, F., and Stordal, F.: Impact of $\mathrm{NO}_{\mathrm{x}}$ emissions from subsonic aircraft: Inclusion of plume processes in a three-dimensional modeling covering Europe, North America and North Atlantic, J. Geophys. Res., 105, 3573-3582, 2000a.

Kraabøl, A. G., Konopka, P., Stordal, F., and Schlager, H.: Modelling chemistry in aircraft plumes 1: comparison with observations and evaluation of a layered approach, Atmos. Environ., 34, 3939-3950, 2000b.

Kraabøl, A. G., Berntsen, T. K., Sundet, J. K., and Stordal, F.: Impacts of $\mathrm{NO}_{\mathrm{x}}$ emissions from subsonic aircraft in a global three-dimensional chemistry transport model including plume processes, J. Geophys. Res., 107, 4655-4667, 2002.

Lawrence, M. G. and Crutzen, P. J.: Influence of $\mathrm{NO}_{\mathrm{x}}$ emissions from ships on tropospheric photochemistry and climate, Nature, 402, 167-170, 1999.

Lee, D., Fahey, D. W., Foster, P. M., Newton, P. J., Wit, R. C. N., Lim, L. L., Owen, B., and Sausen, R.: Aviation and the global climate change in the 21th century, Atmos. Environ., 43, 35203537, 2009.

Lee, D. S., Pitari, G., Grewe, V., Gierens, K., Penner, J. E., Petzold, A., Prather, M. J., Schumann, U., Bais, A., Berntsen, T., Iachetti, D., Lim, L. L., and Sausen, R.: Transport impacts on atmosphere and climate: Aviation, Atmos. Environ., 44, 4678-4743, 2010.

Lewellen, D. C. and Lewellen, W. S.: The Effects of Aircraft Wake Dynamics on Contrail Development, J. Atmos. Sci., 58, 390406, 2001a.

Lewellen, D. C. and Lewellen, W. S.: Effects of aircraft wake dynamics on measured and simulated $\mathrm{NO}_{\mathrm{x}}$ and $\mathrm{HO}_{\mathrm{x}}$ wake chemistry, J. Geophy. Res., 106, 27661-27672, 2001 b.

Lin, K., Trainer, M., and Liu, S. C.: On the nonlinearity of the tropospheric ozone production, J. Geophys. Res., 93, 15879-15888, 1998.

Meijer, E. W.: Modeling the impact of subsonic aviation on the composition of the atmosphere, Ph.D. thesis, Technische Universiteit Eindhoven, 2001.

Meijer, E. W., van Velthoven, P. F. J., Wauben, W. M. F., Beck, J. P., and Velders, G. J. M.: The effect of the conversion of the nitrogen oxides in aircraft exhaust plumes in global models, Geophys. Res. Lett., 24, 3013-3016, 1997.

Meijer, E. W., van Velthoven, P. F. J., Thompson, A. M., Pfister, L., Schlager, H., Schulte, P., and Kelder, H.: Model calculations of the impact of $\mathrm{NO}_{\mathrm{x}}$ from air traffic, lightning, and surface emissions compared with measurements, J. Geophys. Res., 105, 3833-3850, 2000.

Meilinger, S. K., Kärcher, B., and Peter, Th.: Microphysics and heterogeneous chemistry in aircraft plumes - high sensitivity on local meteorology and atmospheric composition, Atmos. Chem. Phys., 5, 533-545, doi:10.5194/acp-5-533-2005, 2005.

Melo, O. T., Lusis, M. A., and Stevens, R. D. S.: Mathematical modelling of dispersion and chemical reactions in a plume - Oxidation of $\mathrm{NO}$ to $\mathrm{NO}_{2}$ in the plume of a power plant, Atmos. Environ., 12, 1231-1234, 1978.

Paoli, R: Modeling and simulation of the environmental impact of aircraft emissions, Institut National Polytechnique de Toulouse CERFACS, Habilitation à Diriger des Recherches thesis, 2010.

Paoli, R., Hélie, J., and Poinsot, T.: Contrail formation in aircraft wakes, J. Fluid Mech., 502, 361-373, 2004.

Paugam, R., Paoli, R., and Cariolle, D.: Influence of vortex dynamics and atmospheric turbulence on the early evolution of a contrail, Atmos. Chem. Phys., 10, 3933-3952, doi:10.5194/acp10-3933-2010, 2010.

Penner, J. E., Lister, D. H., Griggs, D. J., Dokken, D. J., and McFarland, M., eds.: Aviation and the Global Atmosphere, A special report of IPCC (Intergovernmental Panel on Climate Change), Cambridge University Press, 1999.

Petry, H., Hendricks, J., Möllhoff, M., Lippert, E., Meier, A., and Sausen, R.: Chemical conversion of subsonic aircraft emissions in the dispersing plume: Calculation of effective emission indices, J. Geophy. Res., 103, 5759-5772, 1998.

Randeniya, L. K., Vohralik, P. F., and Plumb, I. C.: Stratospheric ozone depletion at northern mid latitudes in the 21 st century: The importance of future concentrations of greenhouse gases 
nitrous oxide and methane, Geophys. Res. Lett., 29, 1051, doi:10.1029/2001GL014295, 2002.

Roache, P. J.: Verification and Validation in Computational Science and Engineering, Hermosa Publishers, Albuquerque, NM, 1998.

Roeckner, E., Arpe, K., Bengtsson, L., Christoph, M., Claussen, M., Dumenil, M., Esch, M., Giorgetta, M., Schlese, U., and Schulzweida, U.: The atmospheric general circulation model ECHAM-4: model description and simulation of present-day climate, Tec. Rep. 218, MPI, 1996.

Sander, R., Kerkweg, A., Jöckel, P., and Lelieveld, J.: Technical note: The new comprehensive atmospheric chemistry module MECCA, Atmos. Chem. Phys., 5, 445-450, doi:10.5194/acp-5445-2005, 2005.

Sausen, R., Isaksen, I., Grewe, V., Lee, D. H. D. S., Myhre, G., Kohler, M. O., Pitari, G., Schumann, U., Stordal, F., and Zerefos, C.: Aviation radiative forcing in 2000: an update on IPCC, Meteorol. Z., 14, 555-561, 2005.

Schlager, H., Konopka, P., Schulte, P., Schumann, U., Ziereis, H., Arnold, F., Klemm, M., Hagen, D., Whitefield, P., and Ovarlez, J.: In situ observations of air traffic emission signatures in the North Atlantic flight corridor, J. Geophys. Res., 102, 1073910750, 1997.

Schlager, H., Baumann, R., Lichtenstern, M., Petzold, A., Arnold, F., Seidel, M., Gurk, C., and Fischer, H.: Aircraft-based trace gas measurements in a primary European ship corridor, in: Proc. International Conference on Transport, Atmos. Clim., Oxford, UK, 2006.

Schulte, P., Schlager, H., Ziereis, H., Schumann, U., Baughcum, S. L., and Deidewig, F.: $\mathrm{NO}_{\mathrm{x}}$ emission indices of subsonic longrange jet aircraft at cruise altitude: in situ measurements and predictions, J. Geophys. Res., 102, 21431-21442, 1997.

Schumann, U., Konopka, P., Baumann, R., Busen, R., Gerz, T., Schlager, H., Schulte, P., and Volkert, H.: Estimate of diffusion parameters of aircraft exhaust plumes near the tropopause from nitric oxide and turbulence measurements, J. Geophys. Res., 100, 14147-14162, 1995.

Schumann, U., Schlager, H., Arnold, F., Baumann, R., Haschberger, P., and Klemm, O.: Dilution of aircraft exhaust plumes at cruise altitudes, Atmos. Environ., 32, 3097-3103, 1998.

Seinfeld, J. N. and Pandis, S. N.: Atmospheric Chemistry and Physics: From Air Pollution to Climate Change, WileyInterscience, 2006.

Simpson, D.: Long-period modelling of photochemical oxidants in Europe: (A) Hydrocarbon reactivity and ozone formation in Europe, (B) On the linearity of country-to-country ozone calculations in Europe, Tech. Rep. EMEP MSC-W Note 1/92, Norway Meteorological Institute, 1992.

Song, C. H., Chen, G., and Davis, D. D.: Chemical evolution and dispersion of ship plumes in the remote marine boundary layer: investigation of sulfur chemistry, Atmos. Environ., 37, 26632679, 2003a.

Song, C. H., Chen, G., Hanna, S. R., Crawford, J., and Davis, D. D.: Dispersion and chemical evolution of ship plumes in the marine boundary layer: investigation of $\mathrm{O}_{3} / \mathrm{NO}_{\mathrm{x}} / \mathrm{HO}_{\mathrm{x}}$ chemistry, $\mathrm{J}$. Geophys. Res., 108, 4143, doi:10.1029/2002JD002216, 2003 b.

Stevenson, D. S., Dentener, F. J., Schultz, M. G., Ellingsen, K., van Noije, T. P. C., Wild, O., Zeng, G., Amann, M., Atherton, C. S., Bell, N., Bergmann, D. J., Bey, I., Butler, T., Cofala, J., Collins, W. J., Derwent, R. G., Doherty, R. M., Drevet,
J., Eskes, H. J., Fiore, A. M., Gauss, M., Hauglustaine, D. A., Horowitz, L. W., Isaksen, I. S. A., Krol, M. C., Lamarque, J.-F., Lawrence, M. G., Montanaro, V., Müller, J.-F., Pitari, G., Prather, M. J., Pyle, J. A., Rast, S., Rodriguez, J. M., Sanderson, M. G., Savage, N. H., Shindell, D. T., Strahan, S. E., Sudo, K., and Szopa, S.: Multimodel ensemble simulations of present-day and near-future tropospheric ozone, J. Geophys. Res., 111, D08301, doi:10.1029/2005JD006338, 2006.

Stockwell, D. Z. and Chipperfiled, M. P.: A tropospheric chemicaltransport model: development and validation of the model transport schemes, Q. J. R. Meteorol. Soc., 125, 1747-1783, 1999.

Stockwell, W. R.: A homogeneous gas phase mechanism for use in a regional acid deposition model, Atmos. Env., 20, 1615-1632, 1986.

Stockwell, W. R., Middleton, P., Chang, J. S., and Tang, X.: The second generation regional acid deposition model chemical mechanism for regional air quality modeling, J. Geophys. Res., 95, 16343-16367, 1990.

Strand, A. and Hov, Ø.: A two-dimensional global study of tropospheric ozone production, J. Geophys. Res., 99, 22877-22895, 1994.

Sundet, J. K.: Model studies with a 3-D global CTM using ECMWF data, Ph.D. thesis, University of Oslo, 1997.

Velders, G. J. M., Heijboer, L. C., and Kelder, H.: The simulation of the transport of aircraft emissions by a three-dimensional global model, Ann. Geophys., 12, 385-393, 1994, http://www.ann-geophys.net/12/385/1994/.

Vestreng, V., Mareckova, K., Kakreka, S., Malchykina, A., and Kukkharchyk, T.: Inventory review 2007, Emission data reported to LRTAP Convention and NEC Directive, Stage 1 and 2 review and Review of PM Inventories in Belarus, Republic of Moldova, Russian Federation and Ukraine, Tech. Rep. EMEP MSC-W 1/2007, Norway Meteorological Institute, 2007.

Vilà-Guerau de Arellano, J., Talmon, A. M., and Builtjes, P. J.-H.: A chemically reactive plume model for the $\mathrm{NO}-\mathrm{NO}_{2}-\mathrm{O}_{3}$ system, Atmos. Environ. Part A, 24, 2237-2246, 1990.

Vohralik, P. F., Randeniya, L. K., Plumb, I. C., and Baughcum, S. L.: Impacts of $\mathrm{NO}_{\mathrm{x}}$ emissions from subsonic aircraft in a global three-dimensional chemistry transport model including plume processes, J. Geophys. Res., 113, D05312, doi:10.1029/2007JD008982, 2008.

von Glasow, R., Lawrence, M. G., Sander, R., and Crutzen, P. J.: Modeling the chemical effects of ship exhaust in the cloudfree marine boundary layer, Atmos. Chem. Phys., 3, 233-250, doi:10.5194/acp-3-233-2003, 2003.

Wauben, W. M. F., van Velthoven, P. F. J., and Kelder, H.: A $3 \mathrm{D}$ chemistry transport model study of changes in atmospheric ozone due to aircraft $\mathrm{NO}_{\mathrm{x}}$ emissons, Atmos. Environ., 31, 18191836, 1997.

Zeng, G. and Pyle, J. A.: Changes in tropospheric ozone between 2000 and 2100 modeled in a chemistry-climate model, Geophys. Res. Lett., 30, 1392-1395, 2003. 